\title{
Educação Técnica e Distribuição de Renda no Espírito Santo
}

\section{Introdução}

A educação técnica é tema recorrente no debate sobre desenvolvimento. No caso de economias com níveis medianos de renda per capita e em que a logística e a indústria pesada ocupam papel de destaque, como a capixaba, a educação técnica desempenha papel central no debate ${ }^{6}$.

Embora nem sempre tenha recebido a mesma atenção em termos de políticas, programas e ações públicas, a educação técnica no Espírito Santo sempre recebeu atenção no debate público. Até 2004, a matrícula nesta modalidade de ensino no estado não chegava a 5\% na educação média, quando no Brasil a média era de $7 \%$ e nas regiões Sul e Sudeste já atingia 10 e 11\% (ver tabela 1), refletindo a pouca atenção que o estado atribuía à educação técnica.

A partir daquele ano, entretanto, ocorre uma mudança radical e, em 2007, a matrícula em educação técnica no estado já era três vezes maior que em 2004, passando de oito mil (5\% na educação média) para 20 mil (15\% na educação média). Esta rápida expansão levou o estado a ocupar não só uma posição bem acima da média nacional, mas também acima da maioria dos estados das regiões Sul e Sudeste. Hoje, com relação à importância dada à educação técnica, o Espírito Santo ocupa, logo abaixo de São Paulo e Rio Grande do Sul, a terceira posição entre as unidades da federação (ver tabela 1).

Santos Neves (IJSN), o Instituto de Pesquisa Econômica Aplicada (IPEA) e, posteriormente, a Secretaria de Assuntos Estratégicos (SAE), de interesse do Comitê Estadual de Educação Profissional do Espírito Santo. Os autores gostariam de agradecer os preciosos comentários, críticas e sugestões da equipe técnica do Instituto Jones, em particular, de Magnus de Castro e Ana Paula Vescovi. Gostaríamos também de agradecer a esta última o incentivo e as orientações, tão oportunos na realização desta pesquisa. Por fim, Andrezza Rosalém e Samuel Franco agradecem o financiamento recebido, resultado de um contrato entre o IJSN e o Instituto de Estudos do Trabalho e Sociedade (IETS). Evidentemente que todas as limitações e imprecisões remanescentes são de responsabilidade dos autores. 


\section{TABELA 1: RELAÇÃO ENTRE O NÚMERO DE MATRÍCULAS DA EDUCAÇÃO TÉCNICA (CONCOMITANTE E SUBSEOUENTE) $)^{1,2}$ E DO ENSINO MÉDIO REGULAR: REGIÕES GEOGRÁFICAS E UNIDADES DA FEDERAÇÃO, 2004-2009}

\begin{tabular}{|c|c|c|c|c|c|c|c|}
\hline \multirow{2}{*}{ Unidades da Federação } & \multicolumn{7}{|c|}{ Relação entre educação técnica e ensino médio regular } \\
\hline & 2004 & 2005 & 2006 & 2007 & 2008 & 2009 & 2010 \\
\hline Brasil & 7,4 & 7,8 & 8,4 & 8,3 & 9,5 & 10,3 & 11,1 \\
\hline Norte & 2,7 & 2,7 & 3,9 & 3,4 & 4,8 & 5,8 & 5,5 \\
\hline Rondônia & 2,6 & 3,4 & 3,4 & 2,9 & 3,1 & 4,9 & 6,2 \\
\hline Acre & 2,8 & 5,2 & 3,6 & 2,8 & 5,4 & 5,4 & 4,8 \\
\hline Amazonas & 4,6 & 4,6 & 7,3 & 7,0 & 9,2 & 10,8 & 9,1 \\
\hline Roraima & 6,5 & 6,0 & 6,7 & 6,3 & 6,1 & 6,7 & 5,3 \\
\hline Pará & 1,4 & 1,2 & 1,6 & 1,6 & 2,4 & 3,1 & 3,5 \\
\hline Amapá & 5,3 & 3,4 & 4,5 & 4,3 & 4,0 & 4,8 & 4,9 \\
\hline Tocantins & 2,6 & 3,1 & 7,1 & 4,4 & 7,9 & 8,7 & 7,8 \\
\hline Nordeste & 2,6 & 2,6 & 3,5 & 3,0 & 3,0 & 3,5 & 4,1 \\
\hline Maranhão & 1,4 & 1,6 & 1,4 & 1,2 & 1,3 & 1,7 & 1,8 \\
\hline Piauí & 3,0 & 2,9 & 2,5 & 5,8 & 5,3 & 7,4 & 9,4 \\
\hline Ceará & 2,2 & 2,1 & 2,7 & 2,9 & 2,9 & 4,0 & 4,3 \\
\hline Rio Grande do Norte & 3,2 & 2,7 & 2,8 & 3,5 & 4,0 & 5,5 & 7,2 \\
\hline Paraíba & 4,3 & 3,4 & 5,3 & 4,8 & 5,0 & 3,1 & 3,7 \\
\hline Pernambuco & 4,3 & 4,5 & 7,3 & 3,6 & 3,5 & 4,2 & 4,6 \\
\hline Alagoas & 3,5 & 2,9 & 5,2 & 1,9 & 2,4 & 2,3 & 2,3 \\
\hline Sergipe & 3,1 & 3,3 & 4,0 & 3,8 & 3,0 & 3,1 & 3,4 \\
\hline Bahia & 1,6 & 1,7 & 2,2 & 2,2 & 2,4 & 2,6 & 3,2 \\
\hline Sudeste & 11,0 & 11,6 & 12,0 & 12,5 & 14,6 & 15,4 & 16,5 \\
\hline Minas Gerais & 8,5 & 9,2 & 9,6 & 9,7 & 12,6 & 13,0 & 15,5 \\
\hline Espírito Santo & 4,7 & 5,6 & 9,4 & 14,5 & 14,7 & 14,7 & 16,9 \\
\hline Rio de Janeiro & 11,2 & 11,4 & 11,2 & 10,6 & 11,6 & 11,8 & 13,7 \\
\hline São Paulo & 12,6 & 13,3 & 13,7 & 14,3 & 16,8 & 17,9 & 18,0 \\
\hline Sul & 10,3 & 12,6 & 13,2 & 13,0 & 13,5 & 15,1 & 15,6 \\
\hline Paraná & 7,0 & 9,4 & 10,0 & 8,9 & 9,5 & 11,0 & 12,0 \\
\hline Santa Catarina & 8,7 & 11,3 & 12,8 & 12,6 & 12,0 & 14,4 & 15,8 \\
\hline Rio Grande do Sul & 14,5 & 16,4 & 16,8 & 17,6 & 18,8 & 20,2 & 19,7 \\
\hline Centro-Oeste & 3,8 & 4,4 & 4,5 & 4,5 & 5,9 & 6,8 & 6,6 \\
\hline Mato Grosso do Sul & 4,9 & 5,1 & 4,5 & 6,2 & 7,7 & 9,2 & 7,6 \\
\hline Mato Grosso & 1,5 & 3,2 & 2,6 & 1,5 & 2,5 & 3,4 & 3,0 \\
\hline Goiás & 3,2 & 3,8 & 4,2 & 4,9 & 4,9 & 5,8 & 6,0 \\
\hline Distrito Federal & 7,2 & 6,7 & 7,7 & 6,1 & 12,3 & 12,0 & 11,9 \\
\hline
\end{tabular}

Fonte: Dados obtidos a partir do Censo Escolar (MEC/INEP) de 2004 a 2010.

Notas:

(1) O número de matrículas inclui todas as dependências administrativas.

(2) O número de matrículas da educação técnica não inclui matrículas de educação técnica integrada ao ensino médio.

6. O Espírito Santo tem sido apontado como o segundo estado brasileiro em capacidade de investimentos, somando-se recursos tanto públicos quanto privados. Seu complexo portuário (o estado possui alguns dos principais portos do Brasil, tais como o de Vitória, Tubarão, Ubu e Capuaba) é considerado um dos mais eficientes do país, escoando produtos não somente do estado, mas também de outras regiões, e Vitória, por ter um porto bem equipado e preços competitivos, acabou se tornando a principal porta de entrada de veículos no mercado brasileiro.

Revista Brasileira de Monitoramento e Avaliação | Número 1 | Janeiro-Junho de 2011 
A despeito da presença constante, muitas vezes central, da educação técnica no debate sobre desenvolvimento, sua importância continua controversa. Existe muito mais receio de que a insuficiência de educação técnica possa frear o crescimento econômico do que propriamente evidência a este respeito. Controvérsias à parte, o fato é que a escassez de mão de obra qualificada é uma preocupação constante de empresários e governo. A escassez certamente eleva os salários dos trabalhadores qualificados, o hiato entre qualificados e não qualificados e, consequentemente, o grau de desigualdade salarial. Se, por um lado, o impacto da escassez de mão de obra qualificada sobre a taxa de crescimento certamente não é favorável, por outro, pode ser de dimensões bastante limitadas. Em última instância, o impacto sobre o crescimento depende da capacidade das empresas de responderem à escassez de mão de obra.

As empresas podem responder por meio da adoção de tecnologias menos intensivas em mão de obra qualificada, ou da importação de mão de obra de outras regiões do país, ou do investimento na formação local, ou da combinação dessas estratégias. Contudo, se há estratégias para as empresas enfrentarem a escassez de mão de obra qualificada, qual a necessidade de uma intervenção pública? Existem duas razões que a justificariam. Em primeiro lugar, embora nada impeça que as empresas se ajustem à escassez de mão de obra qualificada, esse ajuste tem custos que podem ser elevados. Uma empresa que já via poucas vantagens em se instalar ou ampliar suas operações no estado, em função dessa dificuldade adicional, pode optar por não se instalar ou mesmo não expandir sua escala de operações. Nesse caso, a garantia de uma oferta adequada de mão de obra qualificada é uma forma de aumentar a atratividade dos investimentos no estado. Assim, se a escassez de mão de obra qualificada preocupa, na medida em que a atratividade do estado merece atenção, uma saída seria subsidiar os investimentos das empresas e deixar que elas decidam utilizar estes subsídios para adotar tecnologias menos intensivas em mão de obra qualificada, ou importar mão de obra mais cara, ou investir na qualificação dos trabalhadores locais.

Existe, entretanto, outra justificativa para a intervenção pública. Mesmo quando a busca por maior atratividade não é uma questão, a sociedade local pode ter preferência sobre a forma como as empresas irão se ajustar à escassez de mão de obra qualificada. Por exemplo, a importação massiva de mão de obra qualificada pode não ser desejável, uma vez que irá limitar os benefícios destes investimentos para a população nativa. Do ponto de vista local, é preferível formar um trabalhador nativo a importar um qualificado. Também, a adoção de tecnologias pouco intensivas em mão de obra qualificada pode não ser de interesse local, embora, neste caso, a resposta definitiva dependa do tipo de substituição: trata-se de substituir mão de obra qualificada por capital ou por mão de obra não qualificada? Numa sociedade com abundância de mão de obra não qualificada, pode ser desejável a adoção de tecnologias mais intensivas neste tipo de mão de obra. Contudo, quando a substitui- 
ção é por capital, pode ser interesse da sociedade local subsidiar a formação de um maior contingente de mão de obra qualificada desincentivando, assim, as empresas a adotarem outras estratégias de ajuste.

No entanto, identificar se a educação técnica deve ser subsidiada é bem mais fácil do que determinar o quanto se deve subsidiá-la. A dificuldade dessa decisão está intimamente relacionada à percepção de que a demanda por mão de obra qualificada pode ser pouco elástica, no sentido de que pequenas mudanças na oferta de trabalhadores qualificados podem ter grande impacto sobre a remuneração de mercado. Nesse caso, o estímulo à expansão da oferta de trabalhadores qualificados deve ser cuidadoso. Um mercado com demanda inelástica não tem capacidade de absorver excedente. Qualquer excesso de mão de obra levará a quedas acentuadas nos salários dos trabalhadores qualificados e a uma acentuada elevação da sua taxa de desemprego.

Além disso, como os trabalhadores a serem qualificados já têm ou estão em vias de adquirir educação média e, portanto, não pertencem ao contingente mais pobre do estado, deve-se considerar com atenção o impacto distributivo de uma política de subsídios à educação técnica. Como os impactos devem ser mais significativos sobre os trabalhadores no centro da distribuição do que sobre os mais pobres, particular atenção deve ser dada à forma de financiar esses subsídios. Tendo em vista que os benefícios da educação técnica são significativos e, em grande medida, privados, seria recomendável considerar a utilização de mecanismos de recuperação de custos, como, por exemplo, tratar parte das bolsas como empréstimos de longo prazo.

Embora o debate sobre a importância da participação do setor público na educação técnica, em geral, seja claro, o mesmo não se pode dizer sobre a discussão a respeito de como operacionalizá-la. Nesse caso, três dimensões distintas da intervenção do estado se confundem: i) subsídio, ii) seleção de beneficiários e de cursos e iii) provisão de cursos de formação técnica. Pelas várias razões elencadas, pode ser desejável subsidiar a formação técnica. Subsidiá-la, no entanto, não implica que o estado deva ter responsabilidade na definição de quem serão os beneficiários, ou como as vagas a serem subsidiadas devem ser distribuídas entre as diversas áreas profissionais, ou, ainda, que os cursos sejam oferecidos em escolas geridas pelo setor público.

Cada uma dessas três dimensões da intervenção pública requer justificativa própria: a) o interesse em promover maior atratividade para investimentos no estado, b) o interesse em desincentivar a importação de mão de obra qualificada, ou c) o interesse em evitar a adoção de tecnologias que a substituam. Estas, no entanto, não justificam a interferência do estado na seleção de beneficiários e cursos, muito menos na provisão destes cursos em instalações públicas. 
A intervenção do estado na escolha dos beneficiários tem uma justificativa baseada na meritocracia (eficiência) e na equidade. A sociedade certamente gostaria que os mais aptos fossem os primeiros a se beneficiar dos cursos subsidiados (meritocracia) e, em segundo lugar, aqueles que mais precisam (equidade). O ideal seria subsidiar os pobres mais talentosos e perseverantes. Entretanto, na medida em que os mais pobres podem não ser os que mais irão se beneficiar dos subsídios, algum compromisso entre equidade e eficiência terá que ser alcançado para se definir um critério operacional de seleção.

A participação do estado na definição da distribuição dos cursos a serem subsidiados por área profissional é bem mais difícil de justificar, dado que as empresas têm muito mais informação do que o estado. Elas conhecem não só as áreas em que há necessidade de trabalhadores, mas também em quais delas existe maior escassez no mercado. Assim, o ideal seria deixar as empresas decidirem como as vagas em educação técnica a serem subsidiadas devem ser distribuídas entre as diversas áreas, oferecendo, se necessário, a cada uma delas uma parcela para decidir.

Entretanto, de todas as três dimensões, sem dúvida a mais difícil de justificar é a intervenção pública na provisão do serviço. Não é claro por que razão a provisão da educação técnica deve ocorrer numa escola pública. Em princípio, a educação técnica poderia ser financiada pelo estado, mas provida integralmente pelo setor privado, incluindo aí o terceiro setor e o Sistema S.
Em resumo, exceto por alguma voz no processo de seleção dos beneficiários, não é evidente por que o setor público não deveria limitar sua participação ao financiamento, deixando a seleção e a provisão dos cursos por conta do setor privado. Como foi visto, embora o subsídio à educação técnica reduza a escassez de mão de obra qualificada e, desta forma, estimule os investimentos no estado, com este mesmo fim existem outros instrumentos possivelmente mais efetivos. Assim, provavelmente a principal razão para que o estado subsidie a educação técnica é a internalização dos benefícios do desenvolvimento, isto é, a garantia de que a maior parte dos ganhos do crescimento econômico seja apropriada pelas famílias trabalhadoras, em particular, pelas mais pobres.

O objetivo deste estudo é precisamente avaliar em que medida a educação técnica é um instrumento verdadeiramente eficaz para alcançar esta desejada apropriação dos benefícios do crescimento econômico pelos trabalhadores e suas famílias.

Essa avaliação deve necessariamente prosseguir em dois passos. Até o momento, tem-se tomado como dado que a educação técnica promove a produtividade e a empregabilidade dos trabalhadores e, portanto, deve elevar seus salários e reduzir suas chances de ficarem desempregados. Assim, inevitavelmente, o primeiro passo na avaliação deve ser a verificação desta afirmação. Este é o tema tratado na seção 2 deste estudo, que apresenta evidência do impacto da educação técnica sobre a remuneração e a empregabilidade 
dos trabalhadores. Vale ressaltar que os benefícios da educação técnica se espalham por toda a vida laboral dos trabalhadores e, portanto, qualquer avaliação deve considerar os impactos ao longo de todo o ciclo de vida.

A educação técnica, contudo, tem custos tanto para o setor público que a subsidia como para os beneficiários (custos privados). Dentre os custos privados, o mais importante decorre da necessidade que muitas vezes o curso impõe ao beneficiário em postergar sua entrada no mercado de trabalho. Para que a educação técnica tenha relevância econômica, é necessário que o valor presente dos seus benefícios supere os seus custos públicos e privados. Caso contrário, os beneficiários prefeririam uma transferência igual ao subsídio aportado pelo setor público ao invés da vaga no curso. Assim, na seção 3, apresentam-se estimativas da relação custo-benefício para a educação técnica no Espírito Santo.
A importância da educação técnica para a internalização dos benefícios do crescimento não depende apenas da magnitude dos seus impactos sobre seus beneficiários. Sua importância depende também de quantos são os egressos e onde eles se localizariam na distribuição de renda caso não tivessem tido a oportunidade de adquirir educação técnica. Quanto maior o número de concluintes e quanto maior a sua pobreza caso não tivessem acesso à educação técnica, mais importante ela será para a internalização dos benefícios do desenvolvimento do estado. Nesse sentido, a seção 4 apresenta as estimativas do número de concluintes da educação técnica e da sua localização na distribuição de renda do estado caso não tivessem acesso à educação técnica. A seção 5 combina estimativas de impacto obtidas na seção 2 com o número e o posicionamento dos beneficiários na distribuição de renda para obter o impacto da educação técnica sobre a distribuição de renda do estado. Por fim, a última seção apresenta um breve sumário dos principais resultados encontrados.

7. O governo do Espírito Santo concede à população uma bolsa de estudo por meio da Secretaria do Estado da Educação (SEDU) que tem como objetivo priorizar a formação profissional de nível técnico desses jovens. O programa existe desde 2006 e ao todo já oferece cerca de 1.600 vagas para os jovens em escolas públicas do estado. 0 processo de seleção e matrícula de alunos para cursos de educação profissional de nível técnico em instituições privadas no Espírito Santo destina-se aos candidatos que tenham cursado todo o Ensino Médio Regular ou EJA/EM, inclusive CEEJA na rede. $O$ processo seletivo é realizado em duas etapas: análise do questionário socioeconômico e prova objetiva de múltipla escolha, comum a todos os candidatos: Língua Portuguesa (20 pontos), Matemática (15 pontos), Física, Química e Biologia (15 pontos) e avaliação do questionário socioeconômico (20 pontos). O número total de pontos de cada candidato é o resultado da soma dos pontos obtidos em cada componente. Os candidatos são selecionados de acordo com a pontuação obtida e classificados em ordem decrescente até o preenchimento total do número de vagas de cada curso e turno. Ver <http://www.educacao.es.gov.br/download/Edital_bolsa_sedu_Alunos2011.pdf>. Consulta realizada em 11 de março de 2011.

8. Aqui é possível argumentar que o estado pode fazer um planejamento de mais longo prazo, incentivando os investimentos em determinados setores que ele considera estratégicos e, portanto, buscando formar profissionais em áreas específicas.

Revista Brasileira de Monitoramento e Avaliação | Número 1 | Janeiro-Junho de 2011 
Impactos da educação técnica sobre

\section{empregabilidade e remuneração}

Embora o objetivo da educação técnica seja expandir o conhecimento dos alunos, tipicamente ela também tem impacto sobre o seu comportamento e suas atitudes, promovendo a autoestima e o protagonismo e reduzindo a impulsividade, entre outros efeitos sobre as habilidades não cognitivas dos egressos. Dentre eles, no entanto, ressaltam-se os impactos sobre a inserção no mercado de trabalho. Em função da educação que receberam, egressos da educação técnica tornam-se trabalhadores particularmente valorizados no mercado.

Nesta seção, busca-se apresentar estimativas de quão mais valorizados são estes trabalhadores. Vale ressaltar que esta maior valorização não resulta apenas de diferenças cognitivas (egressos da educação técnica têm maior conhecimento sobre determinadas profissões), mas também de diferenças em habilidades não cognitivas estimuladas pela educação técnica, como persistência, pontualidade e autoestima, que influenciam o seu desempenho como trabalhadores.

A valorização dos profissionais no mercado de trabalho dá-se ao longo de várias dimensões. Os mais valorizados recebem ofertas de emprego com maior frequência e, portanto, a menos que também sejam muito mais seletivos, devem apresentar menor taxa de desemprego. Além de re- ceberem propostas com maior frequência, os mais valorizados recebem melhores propostas. São ofertas de emprego com melhor remuneração, maior grau de formalização, um leque mais amplo de benefícios e com maior estabilidade, assim como maiores possibilidades de ascensão e melhores condições de trabalho. Este estudo centra a atenção nas duas principais dimensões da valorização do trabalhador no mercado de trabalho: a) acesso ao trabalho e b) remuneração.

Para medir a remuneração, utilizou-se o salário monetário bruto mensal normalmente recebido. Porém, haja vista que os trabalhadores com educação técnica têm acesso a um conjunto mais amplo de benefícios não monetários, concentrar a atenção no salário monetário pode subestimar os ganhos da educação técnica. Por outro lado, na medida em que os trabalhadores com educação técnica tendem a ocupar postos de trabalho formais e a formalização eleva o salário bruto bem acima do que o trabalhador valoriza (devido a uma série de contribuições e impostos), a comparação entre salários brutos sobre-estima os ganhos da educação técnica.

Para avaliar o impacto da educação técnica sobre o acesso ao trabalho, o ideal seria utilizar o número de ofertas recebidas por unidade de tempo. Como esta informação não se encontra disponível, utiliza-se então a probabilidade de se encontrar ocupado. Como nem todos os adultos se declaram interessados em trabalhar - mas este interesse pode ser influenciado por suas perspectivas no mercado de trabalho -, 
a probabilidade de estar ocupado pode ser definida ao menos de duas formas. Em primeiro lugar, não se leva em conta o interesse por trabalhar e, portanto, considera-se simplesmente a probabilidade de um adulto estar ocupado. Neste caso, incorpora-se ao impacto da educação técnica o efeito que esta possa ter tido sobre o interesse de um adulto pelo trabalho. Em segundo lugar, considera-se a probabilidade de um adulto que deseja trabalhar estar ocupado. Aqui, apenas os adultos que desejam trabalhar (população economicamente ativa) são considerados. O impacto da educação técnica sobre o interesse pelo trabalho não é levado em consideração.

Note que estar ocupado não depende apenas de ter acesso a um trabalho. Depende também de estar disposto a aceitar o trabalho a que teve acesso. Tendo em vista que trabalhadores com maior volume de ofertas se tornam mais seletivos, a utilização da probabilidade de estar ocupado como medida de acesso ao trabalho irá subestimar o efetivo impacto da educação técnica. Em outras palavras, ao elevar o volume de ofertas, a educação técnica deve também tornar o trabalhador mais seletivo, reduzindo, desta forma, o efeito medido sobre a probabilidade de estar ocupado. Vale ressaltar que o que está sendo subestimado não é o impacto sobre a probabilidade de estar ocupado, mas o impacto sobre o acesso ao trabalho. A dificuldade, portanto, não é com a avaliação de impacto per se, mas com o uso da probabilidade de estar ocupado como medida de acesso ao trabalho.

Em suma, o objetivo desta seção é estimar o impacto da educação técnica sobre o acesso ao trabalho (medido pela probabilidade de estar ocupado) e a remuneração (salário monetário bruto) dos trabalhadores. A mensuração do impacto da educação técnica é complexa, uma vez que não é necessariamente igual ao diferencial na taxa de ocupação e remuneração entre trabalhadores com e sem educação técnica. De fato, conforme mostra a tabela 2, existem diversas outras características que podem diferenciar estes dois grupos de trabalhadores. De particular importância é o fato de aqueles com educação técnica terem maior escolaridade. Mesmo que a comparação fosse limitada a trabalhadores com a mesma escolaridade, ainda assim existiriam diferenças marcantes em outros atributos observáveis e, portanto, muito provavelmente também em atributos não observáveis (como motivação, perseverança, pontualidade) altamente valorizados no mercado de trabalho.

Conceitualmente, o impacto da educação técnica sobre um grupo de trabalhadores é definido como a diferença entre o acesso ao trabalho e a remuneração que estes trabalhadores teriam caso tivessem tido acesso a esta formação e o que teriam caso não tivessem tido acesso. A dificuldade inerente em obter estimativas deste impacto é o fato de cada trabalhador ter feito ou não educação técnica. Assim, para 
aqueles que se graduaram em um curso técnico, só é possível observar seu acesso ao trabalho e remuneração tendo o curso técnico, enquanto, para os que não tiveram educação técnica, só se observa seu acesso ao trabalho e remuneração sem o curso. Para se estimar o impacto da educação técnica sobre seus egressos, seria necessário contrastar o acesso e a remuneração destes com o que eles teriam caso não tivessem cursado qualquer educação técnica (o que certamente não pode ser observado). De forma similar, se o objetivo fosse estimar o impacto que a educação técnica teria sobre aqueles que não tiveram acesso, então, seria necessário contrastar o acesso ao trabalho e a remuneração que este grupo teria caso tivesse cursado a educação técnica (não observável) com a que eles efetivamente tiveram.

\section{- TABELA 2: CARACTERÍSTICAS DA POPULAÇÃO DE 25 A 64 ANOS: REGIÃO SUDESTE, 2007}

\begin{tabular}{|c|c|c|c|}
\hline Características & Toda população & $\begin{array}{l}\text { População com curso de } \\
\text { educação técnica }\end{array}$ & $\begin{array}{l}\text { População sem curso de } \\
\text { educação técnica }\end{array}$ \\
\hline \multicolumn{4}{|l|}{ Características pessoais } \\
\hline Sexo (masculino) & 47,4 & 48,9 & 47,3 \\
\hline Cor (branco ou amarelo) & 60,0 & 69,2 & 59,4 \\
\hline Idade & 42 & 39 & 42 \\
\hline \multicolumn{4}{|l|}{ Distribuição etária } \\
\hline 25 a 29 & 16,1 & 21,4 & 15,8 \\
\hline 30 a 34 & 15,0 & 17,2 & 14,9 \\
\hline 35 a 39 & 14,3 & 15,4 & 14,3 \\
\hline 40 a 44 & 14,5 & 15,7 & 14,4 \\
\hline 45 ou mais & 40,0 & 30,2 & 40,6 \\
\hline \multicolumn{4}{|c|}{ Características da educação básica e superior } \\
\hline Escolaridade (em anos de estudo) & 8,1 & 12,3 & 7,9 \\
\hline \multicolumn{4}{|l|}{ Distribuição de escolaridade } \\
\hline Analfabeto funcional & 15,3 & 0,0 & 16,1 \\
\hline Fundamental incompleto & 25,8 & 0,0 & 27,2 \\
\hline Fundamental completo & 12,4 & 0,0 & 13,0 \\
\hline Médio incompleto & 4,2 & 0,0 & 4,4 \\
\hline Médio completo & 25,9 & 62,6 & 23,9 \\
\hline Alguma educação superior & 4,6 & 14,5 & 4,1 \\
\hline Superior completo ou mais & 11,8 & 22,9 & 11,2 \\
\hline \multicolumn{4}{|l|}{ Características regionais } \\
\hline Rio de Janeiro & 20,0 & 15,3 & 20,2 \\
\hline Minas Gerais & 23,7 & 23,3 & 23.7 \\
\hline São Paulo & 52,1 & 56,3 & 51,9 \\
\hline Espírito Santo & 4,2 & 5,1 & 4,2 \\
\hline Área urbana & 92,6 & 98,0 & 92,3 \\
\hline
\end{tabular}


Em qualquer uma das situações, um dos lados da comparação não é observado. Tipicamente se imputa o que teria acontecido a um grupo com base no que efetivamente aconteceu com outro grupo similar (grupo de comparação ou controle) em todos os aspectos, exceto a exposição à educação técnica. Assim, para imputar o que teria acontecido com os que participaram caso não tivessem participado, utiliza-se o que efetivamente aconteceu com um grupo similar que não participou. Desta forma, a dificuldade é transferida para como obter um grupo similar.

Existem duas opções válidas para se obter um grupo similar. Estas opções diferem quanto à possibilidade de ter ou não controle sobre o processo de seleção dos beneficiários. Caso seja possível influir sobre tal processo, a melhor opção seria selecionar beneficiários e não beneficiários ao acaso, com probabilidades que podem, entretanto, depender de características observadas. $\mathrm{O}$ acaso garante que, dentre os trabalhadores com as mesmas características observadas, o grupo não beneficiado tem no momento da seleção idêntica distribuição de atributos que o grupo beneficiado. Portanto, o que irá acontecer com este grupo no futuro é exatamente o que ocorreria com o grupo beneficiado caso não tivesse adquirido educação técnica. Assim, esse é um grupo de comparação ideal e, por isso, denomina-se grupo de controle.
Se o processo de seleção não pode ser controlado, então, a melhor opção é documentá-lo completamente. Quando este é conhecido, pode-se determinar a natureza das diferenças entre beneficiários e não beneficiários e então corrigi-las em acesso ao trabalho e remuneração para que espelhem apenas o impacto da educação técnica. As dificuldades neste caso se relacionam à necessidade de conhecer com detalhes o processo de seleção utilizado e ser capaz de construir um modelo estatístico capaz de representá-lo adequadamente. Raramente, entretanto, pode-se contar com informações sobre o processo de seleção que sejam detalhadas o suficiente para permitir a construção de modelos estatísticos capazes de extrair o impacto da educação técnica das diferenças observadas em acesso ao trabalho e remuneração entre participantes e não participantes.

Para efeito deste estudo, nenhuma informação sobre o processo de seleção dos beneficiários da educação técnica encontra-se disponível. A única informação acessível que contém simultaneamente informações sobre acesso ao trabalho, remuneração e educação técnica provém de entrevistas realizadas em outubro de 2007 em uma amostra de trabalhadores de todo o país. Trata-se da Pesquisa Nacional por Amostra de Domicílios (PNAD) de 2007 e seu suplemento sobre educação profissional'.

9. No suplemento da PNAD-2007, há três tipos de informação sobre educação profissional. Neste estudo, utilizou-se apenas as informações referentes a curso técnico de nível médio.

Revista Brasileira de Monitoramento e Avaliação | Número 1 | Janeiro-Junho de 2011 
Com base nessa informação, realizou-se um procedimento em dois passos. Primeiro, estimou-se como a taxa de ocupação e a remuneração dos trabalhadores com e sem educação técnica variam com atributos observáveis que reconhecidamente encontram-se associados a estes resultados. Os atributos considerados foram gênero, cor, idade, escolaridade, unidade da federação em que vive e se vive em área urbana ou rural. Mais especificamente, foram estimadas as regressões (dadas no quadro de equações I), em que $O=1$ indica que a pessoa encontra-se ocupada, $E A=1$ indica que a pessoa encontra-se economicamente ativa, $w$ denota a remuneração monetária mensal e $T$ é um indicador de se a pessoa tem ou não educação técnica. Além disso, $G, C, I, E, U, A$ denotam os seis atributos observáveis: gênero, cor, idade, escolaridade, unidade da federação e residência na área urbana ou rural. Por fim, $f_{T}, g_{T}$ e $h_{T}$ denotam funções a serem estimadas.
Em seguida, com base nos resultados deste primeiro passo, estimou-se o diferencial na taxa de ocupação e remuneração entre trabalhadores com e sem educação técnica que possuem os mesmos atributos observáveis (utilizados na análise realizada no primeiro passo). Mais especificamente, denotando por $T=1$, quando a pessoa tem educação técnica, e por $T=0$, quando não tem, o diferencial em taxa de ocupação e remuneração entre trabalhadores com e sem educação técnica que possuem os mesmos atributos (dado no quadro de equações II), em que $\Delta \mathrm{O}(G, C, I, E, U, A)$ e $\Delta \mathrm{D}(G, C, I, E, U, A)$ denotam os diferenciais na taxa de ocupação referentes à população em idade ativa e economicamente ativa, respectivamente. Os diferencias são sempre entre pessoas com e sem educação técnica que possuem os mesmos atributos, $G, C, I, E, U, A$. De forma similar, $\Delta \mathrm{W}(G, C, I, E, U, A)$ indica o diferencial em remuneração entre trabalhadores com e

\section{OUUADRO DE EOQUAÇÕES I}

$$
\begin{aligned}
& \operatorname{Ln}\left(\frac{P[O=1 \mid G, C, I, E, U, A, T]}{1-P[O=1 \mid G, C, I, E, U, A, T]}\right)=f_{T}(G, C, I, E, U, A) \\
& \operatorname{Ln}\left(\frac{P[O=1 \mid G, C, I, E, U, A, T, E A=1]}{1-P[O=1 \mid G, C, I, E, U, A, T, E A=1]}\right)=g_{T}(G, C, I, E, U, A) \\
& E[\operatorname{Ln}(w) \mid G, C, I, E, U, A, T, O=1]=h_{T}(G, C, I, E, U, A)
\end{aligned}
$$

\section{QQUADRO DE EQUUAÇÕES II}

$$
\begin{aligned}
& \Delta \mathrm{O}(G, C, I, E, U, A)=\frac{\operatorname{Exp}\left(f_{1}(G, C, I, E, U, A)\right)}{1+\operatorname{Exp}\left(f_{1}(G, C, I, E, U, A)\right)}-\frac{\operatorname{Exp}\left(f_{0}(G, C, I, E, U, A)\right)}{1+\operatorname{Exp}\left(f_{0}(G, C, I, E, U, A)\right)} \\
& \Delta \mathrm{D}(G, C, I, E, U, A)=\frac{\operatorname{Exp}\left(g_{1}(G, C, I, E, U, A)\right)}{1+\operatorname{Exp}\left(g_{1}(G, C, I, E, U, A)\right)}-\frac{\operatorname{Exp}\left(g_{0}(G, C, I, E, U, A)\right)}{1+\operatorname{Exp}\left(g_{0}(G, C, I, E, U, A)\right)} \\
& \Delta \mathrm{W}(G, C, I, E, U, A)=\operatorname{Exp}\left(h_{1}(G, C, I, E, U, A)\right)-\operatorname{Exp}\left(h_{0}(G, C, I, E, U, A)\right)
\end{aligned}
$$


sem educação técnica que possuem os mesmos atributos, $G, C, I, E, U, A$.

Esses diferenciais são as correspondentes diferenças brutas entre trabalhadores com e sem educação técnica expurgadas das disparidades devidas às diferenças nos demais atributos observados. Na medida em que o diferencial bruto entre trabalhadores com e sem educação técnica é igual ao impacto da educação técnica acrescido de diferenças devidas às disparidades em outros atributos observados, então, o procedimento proposto permite isolar o impacto da educação técnica. É possível demonstrar que este é o caso, desde que, dentre trabalhadores com idênticos atributos observados, o processo de seleção de beneficiários tenha sido realizado ao acaso (seleção nos observáveis). Contudo, muito provavelmente a seleção não foi ao acaso, nem entre candidatos com mesmos atributos observados. Prova- velmente, entre candidatos com atributos idênticos observados, aqueles mais talentosos, motivados e persistentes devem ter tido maior chance de acesso. Se este foi o caso, então as estimativas apresentadas na sequência devem sobre-estimar o impacto da educação técnica.

Embora a PNAD cubra todo o território nacional, com vistas em limitar a necessidade de controlar por diferenças regionais e de obter estimativas mais adequadas às condições do mercado de trabalho capixaba, restringimos a análise à região Sudeste. A amostra da PNAD nesta região contém 60 mil pessoas entre 25 e 64 anos, 46 mil economicamente ativas nessa faixa etária e 40 mil ocupadas nesta faixa. Estas são as amostras utilizadas para estimar o impacto da educação técnica sobre a taxa de ocupação e a remuneração.

\section{QUUADRO DE EQUUAÇÕES III}

$$
\begin{aligned}
& f_{T}(G, C, I, E, U, A)=a_{1 T}(G)+a_{2 T}(C)+a_{3 T}(I)+a_{4 T}(E)+a_{5 T}(U)+a_{6 T}(A) \\
& g_{T}(G, C, I, E, U, A)=b_{1 T}(G)+b_{2 T}(C)+b_{3 T}(I)+b_{4 T}(E)+b_{5 T}(U)+b_{6 T}(A) \\
& h_{T}(G, C, I, E, U, A)=c_{1 T}(G)+c_{2 T}(C)+c_{3 T}(I)+c_{4 T}(E)+c_{5 T}(U)+c_{6 T}(A)
\end{aligned}
$$

- QuAdRo DE EQUAÇÕES IV

$$
\begin{aligned}
& f_{T}(G, C, I, E, U, A)=a_{1}(G)+a_{2}(C)+a_{3}(I)+a_{4}(E)+a_{5}(U)+a_{6}(A)+\alpha . T \\
& g_{T}(G, C, I, E, U, A)=b_{1}(G)+b_{2}(C)+b_{3}(I)+b_{4}(E)+b_{5}(U)+b_{6}(A)+\beta . T \\
& h_{T}(G, C, I, E, U, A)=c_{1}(G)+c_{2}(C)+c_{3}(I)+c_{4}(E)+c_{5}(U)+c_{6}(A)+\gamma \cdot T
\end{aligned}
$$


TABELA 3: IMPACTO DAS CARACTERÍSTICAS PESSOAIS, EDUCACIONAIS E REGIONAIS SOBRE A REMUNERAÇÃO DO TRABALHO E A TAXA DE OCUPAÇÃO DA POPULAÇÃO DE 25 A 64 ANOS: REGIÃO SUDESTE, 2007

\begin{tabular}{|c|c|c|c|c|c|c|c|c|c|}
\hline \multirow{2}{*}{ Variáveis explicativas } & \multicolumn{3}{|c|}{$\begin{array}{c}\text { Log da remuneração do trabalho entre } \\
\text { ocupados com renda positiva }\end{array}$} & \multicolumn{3}{|c|}{$\begin{array}{c}\text { Taxa de ocupação entre a população } \\
\text { economicamente ativa }\end{array}$} & \multicolumn{3}{|c|}{$\begin{array}{c}\text { Taxa de ocupação entre a população em } \\
\text { idade ativa } \\
\end{array}$} \\
\hline & Coeficiente & P-valor (\%) & Média & Coeficiente & P-valor (\%) & Média & Coeficiente & P-valor (\%) & Média \\
\hline Variável dependente (média) & - & - & 6,7 & - & - & 0,1 & - & - & 0,7 \\
\hline Intercepto & 3,844 & 0 & 0,0 & $-0,159$ & 64 & 0 & $-3,080$ & 0 & 0 \\
\hline \multicolumn{10}{|l|}{ Caracteristicas pessoais } \\
\hline Sexo (homem) & 0,539 & 0 & 0,6 & 0,776 & 0 & 0,5 & 1,431 & 0 & 0,5 \\
\hline Cor (branco ou amarelo) & 0,131 & 0 & 0,6 & 0,090 & 3 & 0,6 & $-0,114$ & 0 & 0,6 \\
\hline Idade & 0,063 & 0 & 40 & 0,124 & 0 & 40 & 0,213 & 0 & 42 \\
\hline Idade ao quadrado & $-0,001$ & 0 & 1724 & $-0,001$ & 0 & 1724 & $-0,003$ & 0 & 1866 \\
\hline \multicolumn{10}{|l|}{ Caracteristicas educacionais } \\
\hline Escolaridade (em anos de estudo) & 0,079 & 0 & 8,7 & 0,092 & 2 & 8,6 & 0,126 & 0 & 8,1 \\
\hline Escolaridade ao quadrado & $-0,007$ & 0 & 94 & $-0,019$ & 0 & 93 & $-0,016$ & 0 & 86 \\
\hline Escolaridade ao cubo & 0,001 & 0 & 1143 & 0,001 & 0 & 1127 & 0,001 & 0 & 1024 \\
\hline $\begin{array}{l}\text { Concluiu curso de educação } \\
\text { técnica }\end{array}$ & 0,106 & 0 & 0,1 & 0,250 & 1 & 0,1 & 0,218 & 0 & 0,1 \\
\hline \multicolumn{10}{|l|}{ Características regionais } \\
\hline Rio de Janeiro & 0,016 & 28 & 0,2 & $-0,057$ & 50 & 0,2 & $-0,157$ & 0 & 0,2 \\
\hline Minas Gerais & $-0,063$ & 0 & 0,2 & 0,334 & 0 & 0,2 & 0,120 & 1 & 0,2 \\
\hline São Paulo & 0,145 & 0 & 0,5 & 0,144 & 8 & 0,5 & 0,002 & 96 & 0,5 \\
\hline Área urbana & 0,235 & 0 & 0,9 & $-1,085$ & 0 & 0,9 & $-0,672$ & 0 & 0,9 \\
\hline Número de observaçōes & & 40.165 & & & 46.024 & & & 60.271 & \\
\hline$R^{2}$ & & 0,45 & & & - & & & - & \\
\hline
\end{tabular}

Com intuito de facilitar a estimação dessas relações, uma série de simplificações foi incorporada. Em primeiro lugar, assumiu-se que cada uma das funções é separável em seus argumentos (vide quadro de equações III).

Em segundo lugar, assumiu-se que as funções para os que têm e os que não têm educação técnica são paralelas (vide quadro de equações IV).

Neste caso, $\alpha$ e $\beta$ são os parâmetros que captam o impacto da educação técnica sobre as taxas de ocupação na população em idade ativa e na população economicamente ativa, respectivamente, e $\gamma$ capta o impacto da educação técnica sobre a remuneração dos ocupados. De acordo com a metodologia utilizada, a educação técnica terá impactos positivos e estatis- ticamente significativos sobre a taxa de ocupação e a remuneração se, e somente se, estes parâmetros forem positivos e estatisticamente significantes. Por fim, supôs-se que as relações com a idade, $a_{3}$, $b_{3}$ e $c_{3}$, são quadráticas e aquelas com a escolaridade, $a_{4}, b_{4}$ e $c_{4}$ são cúbicas.

As estimativas obtidas e seu grau de significância estatística são apresentados na tabela 3. Conforme esta tabela revela, supondo válidos os pressupostos que dão suporte à metodologia utilizada, a educação técnica eleva tanto a taxa de ocupação como a remuneração dos trabalhadores. Devido a não linearidade dos modelos estimados, a interpretação dos parâmetros torna-se um pouco mais complexa. No caso da remuneração, dada a especificação logarítmica utilizada, o impacto estimado $(\gamma)$ de 0,106 significa 


\section{- GRÁFICO 1: PERFIL ETÁRIO DA REMUNERAÇÃO DO TRABALHO DA POPULAÇÃO DE 25 A 64 ANOS SEGUNDO CARACTERÍSTICAS PESSOAIS: ESPÍRITO SANTO, 2007}

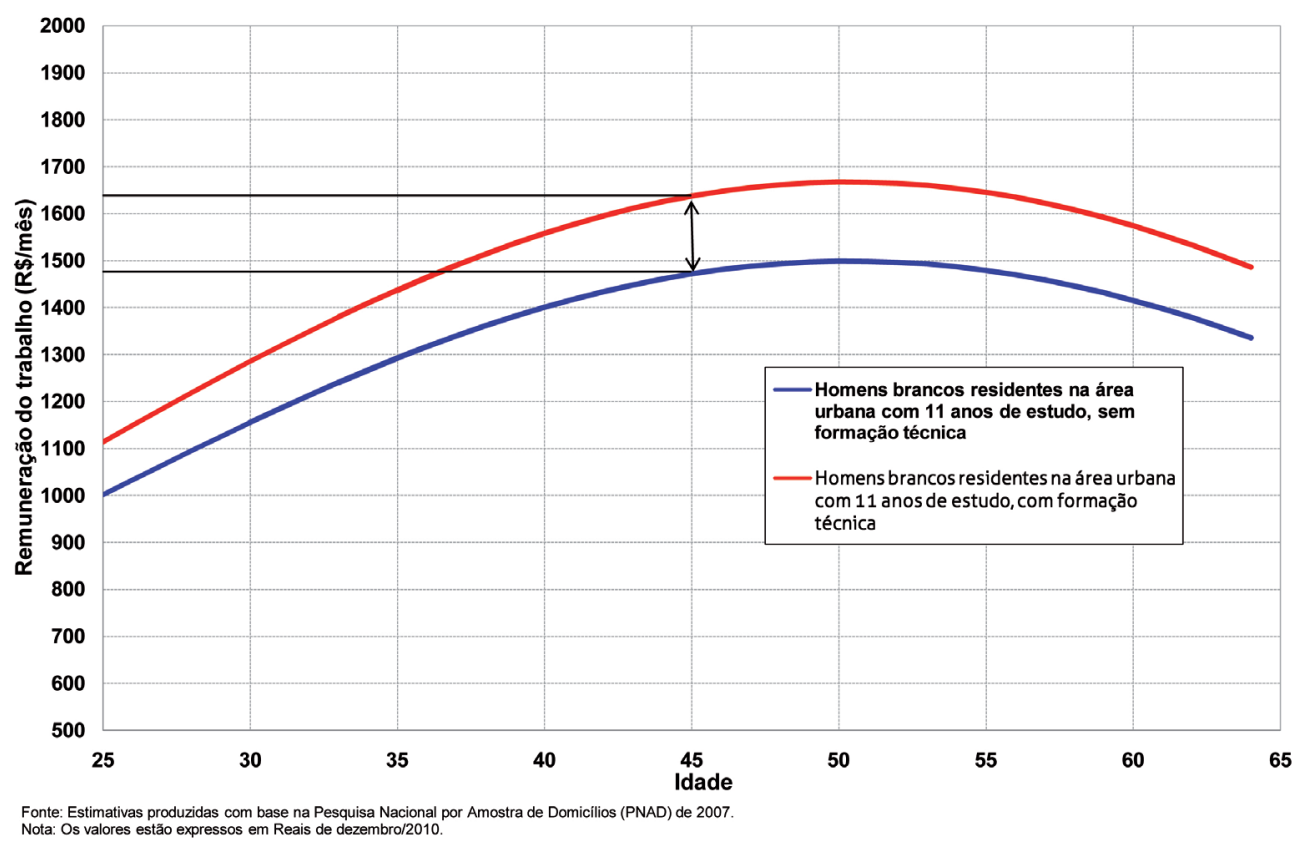

que, em média (geométrica), os trabalhadores com educação técnica recebem uma remuneração $11 \%(100(\operatorname{Exp}(\gamma)-1))$ superior a dos trabalhadores sem educação técnica com os mesmos atributos. Com vistas em tornar a interpretação da estimativa do impacto da educação técnica mais fácil, apresenta-se, no gráfico 1 , como a remuneração média (geométrica) referente a homens brancos, apenas com educação média completa e residentes na área urbana do Espírito Santo varia ao longo de seu ciclo de vida, dependendo se têm ou não educação técnica. Conforme o gráfico 1 revela, aos 45 anos de idade, a remuneração mensal daqueles com educação técnica é $\mathrm{R} \$ 165,00$ superior a dos trabalhadores sem educação técnica com os mesmos atributos observáveis.

No caso da taxa de ocupação referente à população em idade ativa, dada a especificação logística adotada, o impacto estimado $(\alpha)$ de 0,218 significa que a razão de chances de estar ocupado para pessoas com educação técnica é $24 \%(100(\operatorname{Exp}(\alpha)-1)$ ) superior a daquelas sem educação técnica com os mesmos atributos. Assim, se $75 \%$ da população sem educação técnica com dados atributos encontra-se ocupada (o que implica uma razão de chances de três para um), então $79 \%$ da população com educação técnica com os mesmos atributos deverá estar ocupada (o que implica uma 


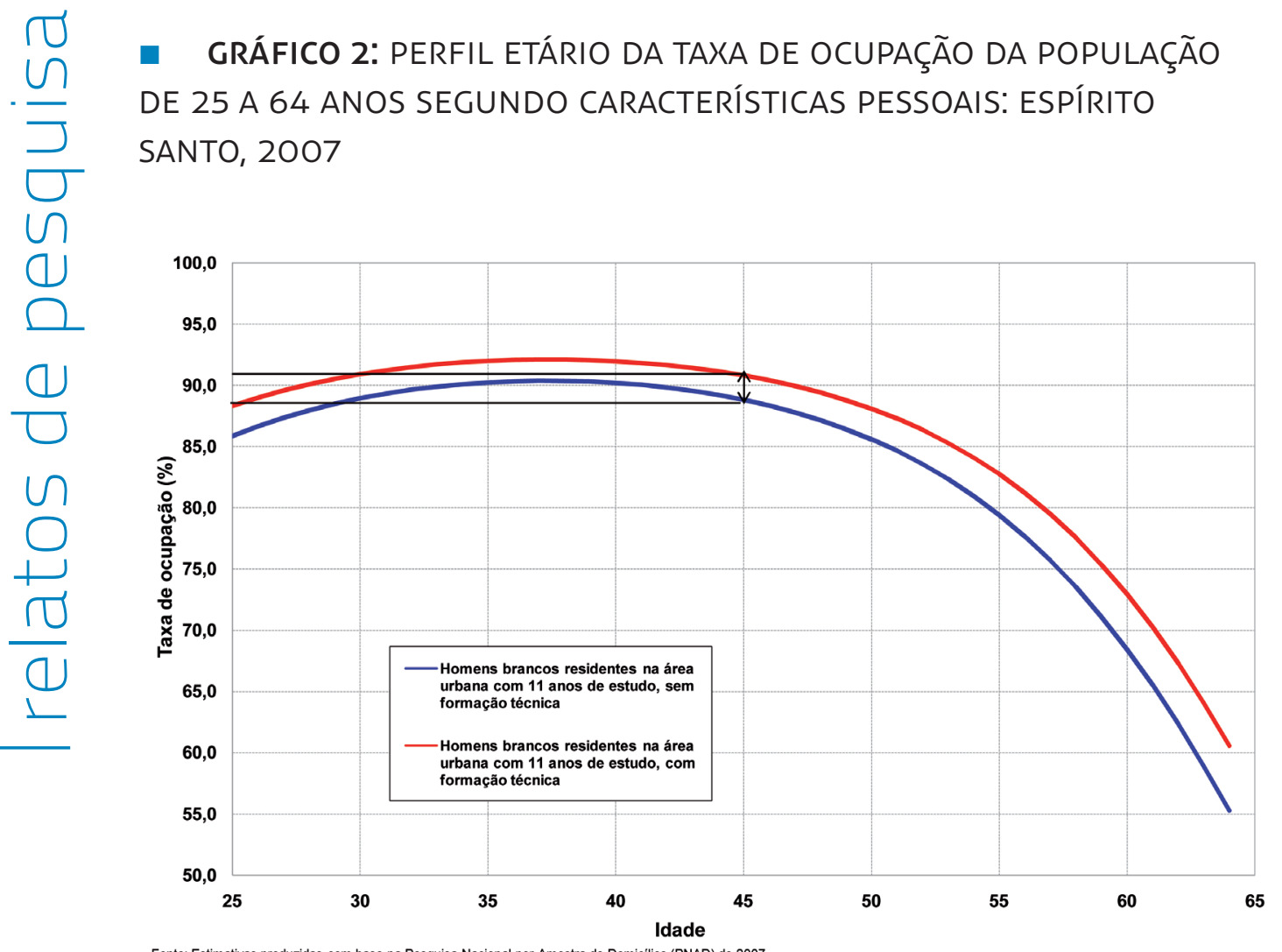

Fonte: Estimativas produzidas com base na Pesquisa Nacional por Amostra de Domicilios (PNAD) de 2007.

- GRÁFICO 3: PERFIL ETÁRIO DA TAXA DE OCUPAÇÃO DA POPULAÇÃO ECONOMICAMENTE ATIVA DE 25 A 64 ANOS SEGUNDO CARACTERÍSTICAS PESSOAIS: ESPÍRITO SANTO, 2007

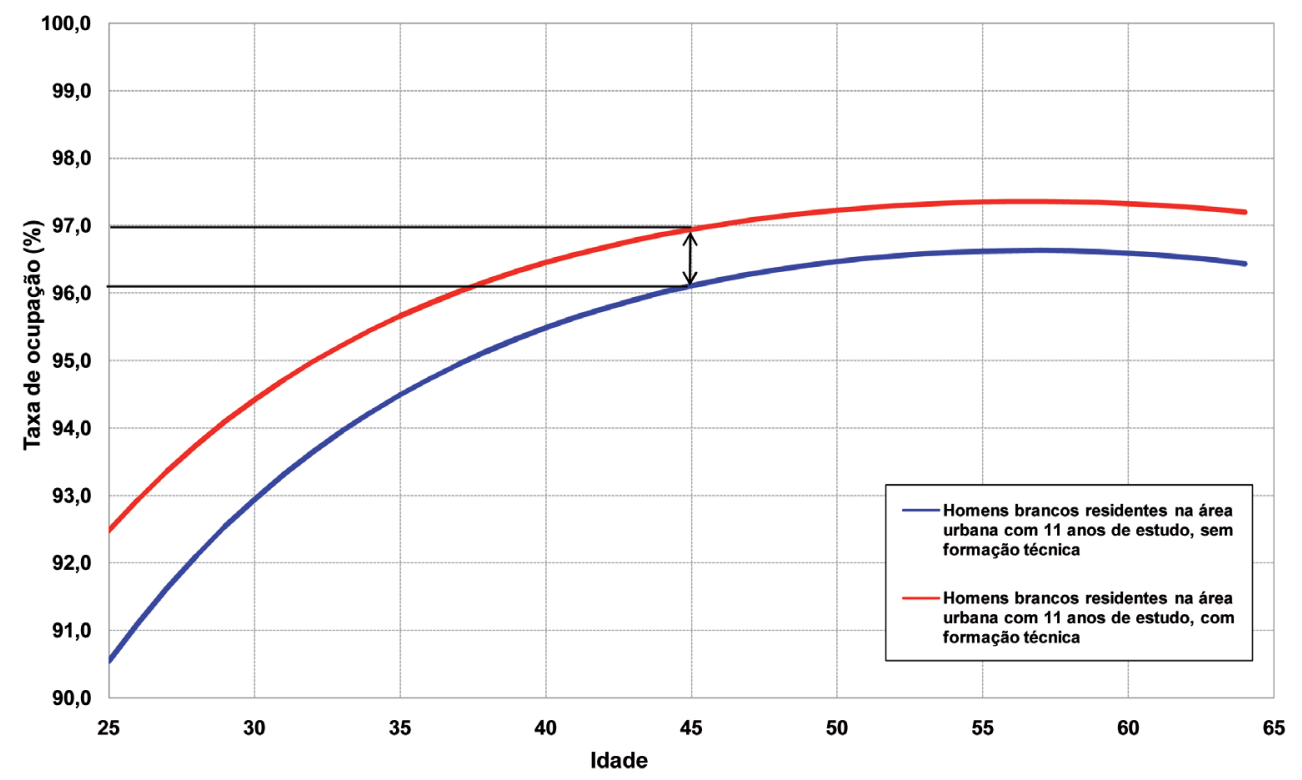


razão de chances de 3,7 para um, portanto, $24 \%$ maior). Com vistas em facilitar a interpretação do impacto estimado, o gráfico 2 apresenta a taxa de ocupação referente a homens brancos, apenas com educação média completa e residentes na área urbana do Espírito Santo que varia ao longo de seu ciclo de vida, dependendo se têm ou não educação técnica. Aos 45 anos de idade, a taxa de ocupação daqueles com educação técnica é dois pontos percentuais superior a dos trabalhadores sem educação técnica com os mesmos atributos observáveis.

De forma similar, no caso da taxa de ocupação referente à população economicamente ativa, dada a especificação logística também adotada, o impacto estimado $(\beta)$ de 0,250 significa que a razão de chances de estar ocupado para pessoas com educação técnica é $31 \%$ $(100(\operatorname{Exp}(\beta)-1))$ superior a daquelas sem educação técnica com os mesmos atributos. Assim, se $80 \%$ da população economicamente ativa sem educação técnica com dados atributos encontra-se ocupada (o que implica uma razão de chances de quatro para um), então $84 \%$ da população economicamente ativa com educação técnica com os mesmos atributos deverá estar ocupada (o que implica uma razão de chances de 5,3 para um, portanto, 31\% maior). O gráfico 3 apresenta a taxa de ocupação referente a homens brancos, apenas com educação média completa e residentes na área urbana do Espírito Santo que varia ao longo de seu ciclo de vida, dependendo se têm ou não educação técnica. Aos 45 anos de idade, a taxa de ocupação daqueles com educação técnica é um ponto percentual superior a dos trabalhadores sem educação técnica com os mesmos atributos observáveis.

\section{Propensão a pagar pela educação técnica}

Na seção anterior, estimou-se o impacto da educação técnica sobre a empregabilidade e a remuneração. Entretanto, conforme ressaltado, a metodologia utilizada é limitada. Ela pressupõe que, dentre os indivíduos com idênticos atributos observáveis, todos tiveram a mesma chance de obter educação técnica. Na medida em que os mais motivados, talentosos e perseverantes tiveram maior chance, as estimativas obtidas na seção anterior estarão sobre-estimadas. Neste caso, elas incorporam além da influência da educação técnica, o impacto dos egressos já serem mais talentosos, perseverantes, motivados, entre outros atributos, mesmo antes de realizarem o curso.

A magnitude dos impactos encontrados, entretanto, é elevada. Segundo as estimativas da seção anterior, a educação técnica eleva a remuneração em $11 \%$ e a taxa de ocupação em 5 pontos percentuais. Este impacto mostra-se ainda mais expressivo quando se reconhece sua influência na inserção no mercado de trabalho ao longo de todo o ciclo de vida do trabalhador. O custo da educação técnica, entretanto, tampouco é desprezível. Estima-se um gasto público de aproximadamente $\mathrm{R} \$ 300,00$ por mês 


\section{TABELA 4: CUSTO MENSAL POR ALUNO DO PROGRAMA BOLSA SEDU SEGUNDO O CURSO: ESPÍRITO SANTO, 2010}

\begin{tabular}{|c|c|c|}
\hline Curso técnico & Custo mensal por aluno (R\$) & Custo total (RS) \\
\hline Mecânica & 306 & 5.512 \\
\hline Logística & 272 & 4.902 \\
\hline Eletrotécnica & 323 & 5.810 \\
\hline Eletrônica & 308 & 5.537 \\
\hline Automação Industrial & 323 & 5.810 \\
\hline Química & 303 & 5.461 \\
\hline Química (Petróleo e Gás) & 303 & 5.461 \\
\hline Enfermagem & 271 & 4.882 \\
\hline Metalurgia & 333 & 5.985 \\
\hline Edificações & 320 & 5.752 \\
\hline Design de Interiores & 271 & 4.882 \\
\hline Design de Móveis & 287 & 5.170 \\
\hline Custo médio & 302 & 5.430 \\
\hline
\end{tabular}

Fonte: Edital SEDU, Portaria no 1826-S, de 21/12/2009.

Nota: Os cursos em média possuem duração de 18 meses.

de curso (ver tabela 4) e, portanto, cerca de R\$ 5.400,00 para um curso de 18 meses. Além disso, existem os gastos privados relacionados a transportes, material escolar, livros, dentre outras despesas necessárias para frequentar o curso, principalmente devido à necessidade de adiar a entrada no mercado de trabalho. Assim, com intuito de verificar em que medida os benefícios da educação técnica superam seus custos, é necessário obter um indicador sintético, escalar, que represente ao menos o conjunto dos impactos da educação técnica sobre a empregabilidade, a remuneração e outros aspectos da inserção no mercado de trabatho ao longo de todo o ciclo de vida do trabalhador. Embora a educação técnica tenha também impactos sobre outras dimensões da vida de seus egressos, seu objetivo central é promover uma melhor inserção no mercado de trabalho. Por este motivo, não constitui uma severa deficiência limitar a atenção apenas aos impactos sobre a inserção no mercado de trabalho.
A obtenção de um indicador sintético dos benefícios da educação técnica enfrenta duas dificuldades. Primeiro, o fato de os impactos incidirem sobre duas dimensões da inserção no mercado de trabalho: i) probabilidade de obter um emprego e ii) remuneração. Segundo, o fato de os impactos estarem distribuídos ao longo de toda a vida do trabalhador. Em princípio, o valor relativo dado à segurança com que tem acesso ao trabalho e à remuneração que irá receber varia de trabalhador para trabalhador. Os mais avessos ao risco irão dar maior importância à segurança com que têm acesso ao trabalho, enquanto os menos avessos ao risco irão dar maior peso à remuneração.

Com o objetivo de simplificar essa avaliação, supôs-se que os trabalhadores são neutros com relação ao risco e, portanto, importam-se apenas com o valor esperado de sua remuneração. Caso houvesse 
apenas um momento no tempo, a remuneração de um trabalhador, $M$, seria dada pelo produto $M=O R$, uma vez que, para se ter remuneração, é necessário antes que se tenha um emprego, $O=1$. Neste caso, para o conjunto de trabalhadores com atributos $B=b$, o valor esperado da remuneração é dado por:

$E[M \mid B=b]=P[O=1 \mid B=b] E[R \mid O=1, B=b]$

No que segue, considerou-se sempre que estes atributos coincidem com o conjunto observado e utilizado para se estimar o impacto da educação técnica. Por conseguinte, tem-se que $B=(G, C, I, E, U, A)$.

O fato de os impactos da educação técnica ocorrerem ao longo de todo o ciclo de vida do trabalhador também dificulta estimar os seus valores totais. Como no caso da aversão ao risco, também com relação a eventos presentes e futuros, cada trabalhador tem suas próprias preferências. Uns são mais impulsivos e consideram eventos futuros pouco importantes, enquanto outros dão maior valor ao futuro. Além disso, existe a questão da complementaridade ou substitutibilidade entre os eventos presentes e futuros.

Visando simplificar a avaliação, considerou-se, como é tradicional, que o trabalhador trata o presente e o futuro adequadamente descontado como perfeitos substitutos, isto é, que ele tem uma função de utilidade separável no tempo. Neste caso, se $\delta$ denota a taxa de desconto intertemporal, então o valor esperado presente da remuneração dos trabalhadores seria dado por: $\sum_{t=0}^{L} \delta^{t} E\left[M_{t} \mid B_{t}=b_{t}\right]=\sum_{t=0}^{L} \delta^{t} P\left[O_{t}=1 \mid B_{t}=b_{t}\right] E\left[R_{t} \mid O_{t}=1, B_{t}=b_{t}\right]$ Neste caso, é possível obter um indicador escalar do valor total dos benefícios da educação técnica, $V$, via:

$V(\delta, b)=\sum_{t=0}^{L} \delta^{t} E\left[M_{t} \mid B_{t}=b_{t}, T=1\right]-\sum_{t=0}^{L} \delta^{t} E\left[M_{t} \mid B_{t}=b_{t}, T=0\right]$

ou, alternativamente, com base na seguinte expressão:

$$
\begin{aligned}
& V(\delta, b)=\sum_{t=0}^{L} \delta^{t} P\left[O_{t}=1 \mid B_{t}=b_{t}, T=1\right] E\left[R_{t} \mid O_{t}=1, B_{t}=b_{t}, T=1\right]- \\
& \sum_{t=0}^{L} \delta^{t} P\left[O_{t}=1 \mid B_{t}=b_{t}, T=0\right] E\left[R_{t} \mid O_{t}=1, B_{t}=b_{t}, T=0\right]
\end{aligned}
$$

em que $b=\left(b_{0}, \ldots, b_{L}\right)$ denota a evolução dos atributos do trabalhador ao longo de seu ciclo de vida. Na análise que se segue, assumiu-se que todos os atributos permanecem fixos, exceto a idade. Assim, em particular, assumiu-se que os trabalhadores considerados nem migram nem adquirem maior escolaridade ao longo de sua vida produtiva.

Como essa análise deixa explícito, o valor total dos impactos da educação técnica depende da taxa de desconto utilizada e dos atributos do trabalhador. A dependência do valor da educação técnica aos atributos do trabalhador não é surpresa, dado que, devido a não linearidades, tanto os impactos da educação técnica sobre a ocupação como os impactos sobre a remuneração dependem dos atributos do trabalhador. Estimativas do valor total 


\section{U TABELA 5: RETORNO ANUAL DA EDUCAÇÃO TÉCNICA DE NÍVEL MÉDIO: ESPÍRITO SANTO, 2007}

\begin{tabular}{|c|c|c|c|c|c|c|c|c|c|c|c|c|}
\hline \multirow{2}{*}{$\begin{array}{l}\text { Taxas de } \\
\text { desconto } \\
\text { intertemporal }\end{array}$} & \multicolumn{3}{|c|}{ Branco, na ắrea urbana } & \multicolumn{3}{|c|}{ Branco, na área rural } & \multicolumn{3}{|c|}{ Negro, na ấrea urbana } & \multicolumn{3}{|c|}{ Negro, na área rural } \\
\hline & $\begin{array}{l}\text { Sem } \\
\text { educaçăo } \\
\text { técnica }\end{array}$ & $\begin{array}{l}\text { Com } \\
\text { educaçãa } \\
\text { técnica }\end{array}$ & $\begin{array}{l}\text { Benefício da } \\
\text { educaşăo } \\
\text { técnica }\end{array}$ & $\begin{array}{l}\text { Sem } \\
\text { educação } \\
\text { técnica }\end{array}$ & $\begin{array}{l}\text { Com } \\
\text { educaçăo } \\
\text { técnica }\end{array}$ & $\begin{array}{l}\text { Benefício da } \\
\text { educaçẫo } \\
\text { técnica }\end{array}$ & $\begin{array}{l}\text { Sem } \\
\text { educaçāo } \\
\text { tếnica }\end{array}$ & $\begin{array}{l}\text { Com } \\
\text { educaçăa } \\
\text { técnica }\end{array}$ & $\begin{array}{l}\text { Benefício da } \\
\text { educação } \\
\text { técnica }\end{array}$ & $\begin{array}{l}\text { Sem } \\
\text { educaçăo } \\
\text { técnica }\end{array}$ & $\begin{array}{l}\text { Com } \\
\text { educaçăo } \\
\text { técnica }\end{array}$ & $\begin{array}{l}\text { Benefício da } \\
\text { educaçăo } \\
\text { técnica }\end{array}$ \\
\hline \multicolumn{13}{|l|}{ Homens } \\
\hline $5,0 \%$ & 271 & 301 & 30 & 214 & 238 & 24 & 238 & 264 & 27 & 188 & 209 & 21 \\
\hline $7.5 \%$ & 191 & 213 & 21 & 151 & 168 & 17 & 168 & 187 & 19 & 133 & 148 & 15 \\
\hline $10,0 \%$ & 143 & 159 & 16 & 113 & 126 & 13 & 126 & 140 & 14 & 99 & 111 & 11 \\
\hline \multicolumn{13}{|l|}{ Mulheres } \\
\hline $5,0 \%$ & 158 & 176 & 18 & 125 & 139 & 14 & 139 & 154 & 16 & 110 & 122 & 12 \\
\hline $7.5 \%$ & 112 & 124 & 13 & 88 & 98 & 10 & 98 & 109 & 11 & 77 & 86 & 9 \\
\hline $10,0 \%$ & 84 & 93 & 9 & 66 & 74 & 7 & 73 & 82 & 8 & 58 & 65 & 7 \\
\hline
\end{tabular}

dos benefícios da educação técnica para uma variedade de tipos de trabalhadores capixabas segundo gênero, cor e local de residência (urbana e rural) são apresentadas na tabela 5. As estimativas foram obtidas variando a taxa de desconto anual de $5 \%$ a $10 \%$. Embora as estimativas tenham sido obtidas com base na PNAD2007, todas estão expressas em valores de dezembro de 2010. Para efeito destes cálculos, considerou-se que trabalhadores com e sem educação técnica têm educação média completa, mas nenhuma formação superior, e que ambos iniciaram suas vidas produtivas aos 25 anos e irão se aposentar aos 64 anos. Assim, nem o potencial impacto que a educação técnica poderia ter sobre a continuidade dos estudos nem o adiamento que poderia causar sobre o momento de entrada no mercado de trabalho foram considerados.

As estimativas apresentadas na tabela 5 revelam que, em valores de dezembro de 2010, o valor presente esperado dos benefícios da educação técnica varia de RS 7 mil a R\$ 30 mil, dependendo das características do trabalhador e da taxa de desconto utilizada. Como boa parte dos benefícios da educação técnica ocorre no futuro, quanto menor a taxa de desconto utilizada maior a magnitude do valor do benefício total. Além disso, como boa parte destes benefícios é multiplicativa, portanto, maiores em termos absolutos para trabalhadores com maior remuneração e maior empregabilidade, encontrou-se que o valor total dos benefícios é mais elevado para homens brancos nas áreas urbanas e menores para mulheres negras nas áreas rurais. Tipicamente os benefícios são 14\% maiores para os brancos, $70 \%$ maiores para os homens e $26 \%$ maiores nas áreas urbanas que nas rurais. Em conjunto, os benefícios para os homens brancos urbanos são 2,4 vezes os correspondentes benefícios para mulheres negras rurais.

Resta verificar se esses benefícios superam os custos da educação técnica. Conforme já mencionado, um curso técnico custa para o setor público cerca de R\$ 300,00 por mês (ver tabela 4) ${ }^{10}$. Assim, assumindo uma duração típica de 18 meses, chegamos num custo total de aproximadamente R\$ 5.400,00. Estes gastos, 
TABELA 6: RAZÃO CUSTO/BENEFíCIO DA EDUCAÇÃO TÉCNICA DE NÍVEL MÉDIO, CONSIDERANDO UMA TAXA DE CONCLUSÃO DE 50\%: ESPÍRITO SANTO, 2007

\begin{tabular}{|c|c|c|c|c|c|c|c|c|}
\hline \multirow{2}{*}{$\begin{array}{l}\text { Taxas de } \\
\text { desconto } \\
\text { intertemporal }\end{array}$} & \multicolumn{4}{|c|}{ Considerando um custo de $R \$ 300$ aluno/mês } & \multicolumn{4}{|c|}{ Considerando um custo de $R \$ 450$ aluno/mês } \\
\hline & $\begin{array}{l}\text { Branco, na } \\
\text { área urbana }\end{array}$ & $\begin{array}{l}\text { Branco, na } \\
\text { área rural }\end{array}$ & $\begin{array}{c}\text { Negro, na área } \\
\text { urbana }\end{array}$ & $\begin{array}{c}\text { Negro, na área } \\
\text { rural }\end{array}$ & $\begin{array}{l}\text { Branco, na } \\
\text { área urbana }\end{array}$ & $\begin{array}{l}\text { Branco, na } \\
\text { área rural }\end{array}$ & $\begin{array}{c}\text { Negro, na área } \\
\text { urbana }\end{array}$ & $\begin{array}{l}\text { Negro, na área } \\
\text { rural }\end{array}$ \\
\hline \multicolumn{9}{|l|}{ Homens } \\
\hline $5,0 \%$ & 36 & 45 & 40 & 51 & 53 & 67 & 61 & 77 \\
\hline $7,5 \%$ & 50 & 64 & 57 & 72 & 75 & 95 & 86 & 109 \\
\hline $10,0 \%$ & 67 & 85 & 76 & 97 & 101 & 127 & 115 & 145 \\
\hline \multicolumn{9}{|l|}{ Mulheres } \\
\hline $5,0 \%$ & 61 & 77 & 69 & 88 & 91 & 115 & 104 & 132 \\
\hline $7,5 \%$ & 86 & 109 & 98 & 124 & 129 & 163 & 147 & 186 \\
\hline $10,0 \%$ & 115 & 145 & 131 & 166 & 172 & 218 & 196 & 248 \\
\hline
\end{tabular}

entretanto, antecedem os benefícios. Assim, é necessário descontá-los adequadamente para que custos e benefícios sejam comparáveis.

Considerando que a inserção no mercado de trabalho se inicia logo após o término do curso, mesmo assim os gastos foram efetuados nos dois anos anteriores. Por exemplo, considere um curso iniciado em 2008 e concluído em 2009 cujos egressos e não participantes começam a trabathar em 2010. Neste caso, conforme foi visto, na pior hipótese, o valor total dos benefícios da educação em dezembro de 2010 seria de R\$ 7 mil (benefício para uma mulher negra na área rural, caso a taxa de desconto anual fosse de $10 \%$ ). 0 custo teria sido de duas parcelas de RS 2.700, uma em 2008 e outra em 2009. Considerando uma taxa de desconto anual de $10 \%$, o valor agregado do custo no final de 2010 seria de $R \$ 6,2$ mil e, portanto, ainda inferior ao valor total dos benefícios.

A tabela 6 apresenta a razão custo-benefício para os diversos tipos de trabalhadores e cenários para as taxas de desconto consideradas. Os resultados mostram que os custos envolvidos na oferta da educação técnica representam de 170\% (caso das mulheres negras na área rural com alta taxa de desconto) a $40 \%$ (caso dos homens brancos na área urbana com baixa taxa de desconto) dos benefícios. 
- TABELA 7: TAXA DE CONCLUSÃO DOS CURSOS DE EDUCAÇÃO TÉCNICA DE NÍVEL MÉDIO POR TIPO DE SISTEMA E ÁREA DO CURSO: ESPÍRITO SANTO, 2006-2009

\begin{tabular}{lcccc}
\multicolumn{1}{c}{ Tipo de sistema } & Matriculados & Concluintes & Evadidos & Taxa de conclusão (\%) \\
\hline Estadual ${ }^{1}$ & 15.648 & 7.911 & 7.737 & 51 \\
Ambiente, saúde e segurança & 1.214 & 728 & 486 & 60 \\
Apoio educacional & 771 & 439 & 332 & 57 \\
Controle e processos industriais & 224 & 158 & 66 & 71 \\
Gestão e negócios & 7.564 & 3.957 & 3.607 & 52 \\
Hospitalidade e lazer & 1.913 & 969 & 944 & 51 \\
Informação e comunicação & 2.421 & 963 & 1.458 & 40 \\
Infraestrutura & 213 & 132 & 81 & 62 \\
Produção cultural e design & 965 & 404 & 561 & 42 \\
Recursos naturais & 363 & 161 & 202 & 44 \\
\hline Federal2 & 2.322 & 937 & 1.385 & 40 \\
Ambiente, saúde e segurança & 248 & 132 & 116 & 53 \\
Controle e processos industriais & 1.211 & 502 & 709 & 41 \\
Informação e comunicação & 204 & 68 & 136 & 33 \\
Infraestrutura & 491 & 199 & 292 & 41 \\
Recursos naturais & 168 & 36 & 132 & 21 \\
\hline Bolsa SEDU 2 & 717 & 480 & 237 & 67 \\
\hline
\end{tabular}

Fonte: Dados obtidos a partir dos registros administrativos da Secretaria Estadual de Educação e do Instituto Federal do Espírito Santo (IFES) de 2006 a 2009. Nota 1: Os dados referem-se a soma de todos os cursos das escolas estaduais oferecidos entre 2006 e 2009.

- GRÁFICO 4: DISTRIBUIÇÃO ACUMULADA DOS ALUNOS MATRICULADOS EM CURSOS DE EDUCAÇÃO TÉCNICA CONCOMITANTES E SUBSEOQUENTES SEGUNDO A IDADE: ESPÍRITO SANTO, 2008

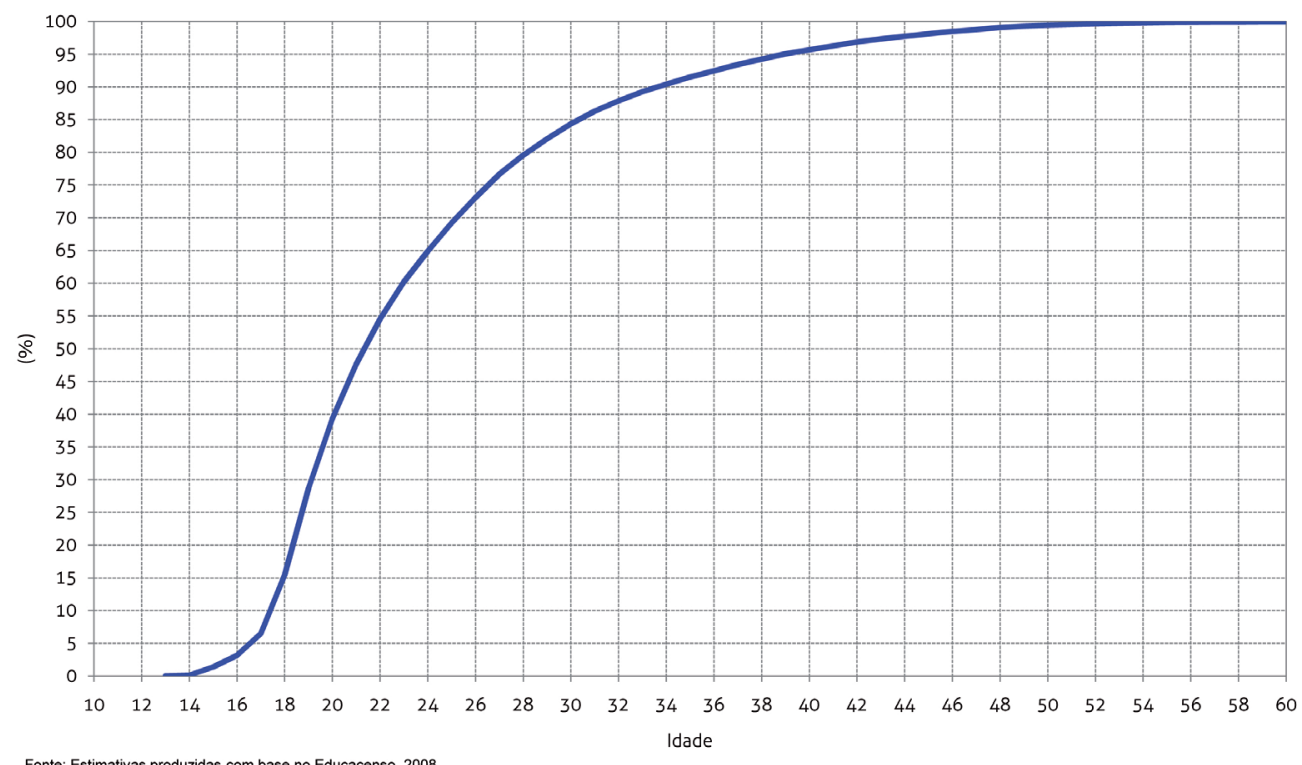




\section{Número de egressos} e sua posição na distribuição de renda

Nas seções anteriores, foi visto que a educação técnica tem grande impacto sobre a empregabilidade e a remuneração e que o custo da oferta destes serviços é apenas uma fração, por vezes pequena, do valor esperado presente destes impactos. O impacto agregado da educação técnica sobre a distribuição de renda, entretanto, não depende apenas do impacto específico sobre cada beneficiário, ele depende também do número de beneficiários e da localização que estes teriam na distribuição de renda caso não tivessem tido acesso à educação técnica. Nesta seção, avalia-se o número de beneficiários e o posicionamento que teriam na distribuição de renda na falta da educação técnica. Na próxima seção, de posse de estimativas do impacto da educação técnica sobre o acesso ao trabalho e a remuneração (seção 2), e da localização e do número de beneficiários, estima-se o seu impacto agregado sobre a distribuição de renda.

De acordo com informações do Censo Escolar, aproximadamente 20 mil jovens encontravam-se matriculados na educação técnica em 2009 (concomitante e subsequente). Destes, nem todos concluirão o curso e apenas alguns se encontravam no último ano. Por conseguinte, a taxa de conclusão para a educação técnica no estado varia de 21 a 71\%, dependendo do tipo de sistema (estadual ou federal) e do curso (ver tabela 7). Para efeito da análise do provável impacto da educação técnica sobre a distribuição de renda, considerou-se um cenário onde apenas metade dos inicialmente matriculados conclui com sucesso o curso, ou seja, estimou-se um número de egressos por ano próximo a 10 mil.

Com o propósito de avaliar a localização que os egressos da educação técnica teriam na distribuição de renda caso não tivessem tido acesso a esta formação, tomou-se como representativa a situação dos atuais trabalhadores jovens (18 a 35 anos) com educação média completa ${ }^{11}$. Para melhor representar a situação deste grupo, a ponderação destes trabalhadores foi ajustada de forma que tivessem a mesma estrutura etária que os jovens atualmente matriculados terão ao concluir o curso. Para simplificar, considerou-se que todos terão concluído o curso em 2 anos.

A estrutura etária dos jovens atualmente matriculados na educação técnica que serve de base para esta análise é apresentada no gráfico 4. Os matriculados na educação técnica no estado são bem mais velhos do que se deveria esperar caso se compusessem exclusivamente por alunos matriculados na educação média (ou que a concluíram recentemente). De fato, cerca de metade dos matriculados têm mais de 21 anos, 30\% têm 25 anos ou mais e

11. Neste grupo estão também incluídos aqueles com educação superior. 


\section{Ð \\ TABELA 8: CARACTERÍSTICAS DA EDUCAÇÃO BÁSICA E SUPERIOR DA POPULAÇÃO DE 25 A 64 ANOS: ESPÍRITO SANTO, 2007}

\begin{tabular}{|c|c|c|c|}
\hline Características & Toda população & $\begin{array}{c}\text { População com curso de educação } \\
\text { técnica }\end{array}$ & $\begin{array}{c}\text { População sem curso de educação } \\
\text { técnica }\end{array}$ \\
\hline Escolaridade (em anos de estudo) & 8,1 & 12,3 & 7,9 \\
\hline \multicolumn{4}{|l|}{ Distribuiç̧ão de escolaridade } \\
\hline Analfabeto funcional & 15,3 & 0,0 & 16,1 \\
\hline Fundamental incompleto & 25,8 & 0,0 & 27,2 \\
\hline Fundamental completo & 12,4 & 0,0 & 13,0 \\
\hline Médio incompleto & 4,2 & 0,0 & 4,4 \\
\hline Médio completo & 25,9 & 62,6 & 23,9 \\
\hline Alguma educaçāo superior & 4,6 & 14,5 & 4,1 \\
\hline Superior completo ou mais & 11,8 & 22,9 & 11,2 \\
\hline
\end{tabular}

Fonte: Estimativas produzidas com base na Pesquisa Nacional por Amostra de Domicílios (PNAD) de 2007

15\% têm idade superior a 30 anos. A idade média dos matriculados na educação técnica no estado é de 24 anos.

O impacto da educação técnica sobre a distribuição de renda depende da posição que estes potenciais candidatos à educação técnica ocupam na própria distribuição. Inicialmente, deve-se reconhecer que todos aqueles que aspiram ser técnicos devem antes ter educação média completa, um nível educacional bem acima da escolaridade média dos trabalhadores capixabas. De fato, como a tabela 8 revela, aproximadamente $42 \%$ da população ocupada no estado tem

TABELA 9: DISTRIBUIÇÃO DOS JOVENS COM AO MENOS O ENSINO MÉDIO COMPLETO POR DÉCIMOS DA DISTRIBUIÇÃO DA POPULAÇÃO SEGUNDO A RENDA PER CAPITA: ESPÍRITO SANTO, 2005-2009

(\%)

\begin{tabular}{|c|c|c|}
\hline Distribuição & Por décimo & Acumulada nos décimos mais pobres \\
\hline Primeiro & 2,5 & 2,5 \\
\hline Segundo & 2,9 & 5,4 \\
\hline Terceiro & 4,6 & 10,0 \\
\hline Quarto & 5,1 & 15,1 \\
\hline Quinto & 7,3 & 22,4 \\
\hline Sexto & 8,2 & 30,6 \\
\hline Sétimo & 11,5 & 42,1 \\
\hline Oitavo & 14,5 & 56,6 \\
\hline Nono & 18,0 & 74,6 \\
\hline Décimo & 25,4 & 100,0 \\
\hline
\end{tabular}

Fonte: Estimativas produzidas com base na Pesquisa Nacional por Amostra de Domicílios (PNAD) de 2005 a 2009. As bases dos diferentes anos foram empilhadas para melhorar a precisão das estimativas. 
educação média completa ${ }^{12}$. Assim, por ter um nível educacional bem acima da média, este grupo dificilmente deveria se localizar entre as famílias mais pobres.

De fato, como revela a tabela 9, apenas $5,4 \%$ se encontram entre os $20 \%$ mais pobres, apenas $10 \%$ entre os $30 \%$ mais pobres e $22 \%$ entre os $50 \%$ mais pobres. Dada esta distribuição dos beneficiários potenciais, não se deve esperar que a educação técnica tivesse grande impacto sobre a renda dos mais pobres ou mesmo sobre a desigualdade. Na verdade, o esperado é que a educação técnica tenha mais impacto sobre renda dos $20 \%$ mais ricos (onde se encontra aproximadamente $1 / 3$ dos potenciais beneficiários) do que sobre os $20 \%$ mais pobres (onde se encontram apenas $5,4 \%$ dos potenciais beneficiários), o que eleva a desigualdade ao invés de reduzi-la.

\section{Impactos agregados da educação técnica}

Como foi visto na seção 3, a educação técnica tem impactos individuais notáveis sobre a empregabilidade e a remuneração daqueles que a concluem. Ela eleva a remuneração dos egressos em $11 \%$ e aumenta a taxa de ocupação em 2 a 4 pontos percentuais, a depender das características sociodemográficas dos beneficiados. Nesta seção, investiga-se o impacto agregado de expansões na formação técnica sobre o mercado de trabatho (taxa de ocupação e distribuição das remunerações) e a distribuição de renda. Este impacto agregado, além de depender dos efeitos diretos sobre os beneficiários (egressos da formação técnica) - ver seção 3 -, depende também do número de beneficiários e de sua localização na distribuição de renda, parâmetros investigados na seção anterior.

Quanto maior o número de concluintes, maior deverá ser o impacto agregado. Como os beneficiários da formação técnica precisam necessariamente ter educação média completa, eles tendem a se localizar nos segmentos mais ricos da população (ver seção 4), levando expansões na formação técnica a terem menor impacto sobre a pobreza e a tenderem a elevar o grau de desigualdade.

O impacto da formação técnica é duradouro, influenciando todo o ciclo de vida dos trabalhadores. Desta forma, para efeito da avaliação de seu impacto agregado, deve-se levar em consideração todos os investimentos realizados em anos anteriores, isto é, o número de beneficiários a ser considerado é o acumulado de todas as coortes de egressos de anos anteriores. Quanto a este aspecto, para efeito da avaliação do impacto agregado de uma expansão na formação técnica, duas alternativas polares foram consideradas. $\mathrm{Na}$ primeira, investigou-se o impacto de um único ano de investimento de magnitude similar ao que tem ocorrido, nos últimos anos, no estado. Isto é, avaliou-se o im-

12. $25,9+4,6+11,8=42,3$.

Revista Brasileira de Monitoramento e Avaliação | Número 1 | Janeiro-Junho de 2011 
pacto agregado da formação técnica de uma única coorte de egressos. Na segunda, investigou-se o impacto que um processo contínuo de investimentos da magnitude do que tem ocorrido no estado, nos últimos anos. Mais especificamente estimou-se como seriam as condições do mercado de trabalho e da distribuição de renda do estado caso o estado em todo o seu passado sempre tivesse adotado uma política de educação técnica tão arrojada quanto a que atualmente adota.

Sabe-se que, nos anos mais recentes, a matrícula na formação técnica concomitante e subsequente ficou próxima a 20 mil alunos por ano. Infelizmente, não se sabe quantos dos inicialmente matriculados terminam a graduação. Entretanto, com base em informações sobre uma amostra (infelizmente não representativa do universo) de turmas em escolas federais, estaduais e particulares (ver tabela 7), estimamos que a taxa de conclusão deve ser próxima a 50\%. Desta forma, o número de egressos da educação técnica no Espírito Santo para os últimos anos foi estimado como sendo da ordem de 10 mil por ano.

\section{IMPACTOS IMEDIATOS DE UMA COORTE DE EGRESSOS}

O primeiro objetivo foi estimar o impacto agregado que resultaria da inserção no mercado de trabalho capixaba de uma nova coorte de 10 mil jovens com formação técnica. Com vistas em operacionalizar esta avaliação, deve-se de imediato reconhecer que nem todos os egressos têm a idade ideal de graduação da educação média, diga-se 17 ou 18 anos. Ao con- trário, a evidência disponível mostra que estes egressos têm em média 24 anos. Assim, ao se obter estimativas do impacto agregado da inserção de uma coorte de egressos da educação técnica no mercado de trabalho capixaba, levou-se em consideração tanto o número de egressos como sua distribuição etária. A distribuição etária destes jovens foi obtida a partir da correspondente distribuição entre os matriculados. Como foi visto na seção 4, embora os matriculados na educação técnica ocupem um amplo leque etário, a vasta maioria (90\%) tem idade entre 16 e 33 anos. Desta forma, distribuiu-se o contingente estimado de concluintes (10 mil) entre essas idades de forma proporcional ao número de matriculados em cada idade. Por fim, adicionou-se dois anos para se obter a idade dos egressos. Neste caso, assumiu-se que tipicamente um aluno irá ingressar no mercado de trabalho (ou se apresentar como um técnico, caso já esteja no mercado) dois anos após ter iniciado a formação técnica.

Com o objetivo de estimar o impacto da inserção desta coorte no mercado de trabalho, 10 mil jovens, com educação média completa e com a distribuição etária definida da forma descrita anteriormente, foram selecionados e tiveram sua empregabilidade e remuneração devidamente aumentadas, simulando, desta forma, o impacto individual da educação técnica. Em princípio, até entre jovens de mesma idade, os que procuram e concluem a educação técnica são distintos dos que não procuram ou evadem. Entretanto, como muitas destas diferenças não são conhecidas ou operam em variáveis não observá- 
TABELA 10: IMPACTO IMEDIATO DE UMA COORTE DE EGRESSOS DA EDUCAÇÃO TÉCNICA SOBRE A TAXA DE OCUPAÇÃO E A REMUNERAÇÃO MÉDIA DE JOVENS ENTRE 18 E 35 ANOS: ESPÍRITO SANTO, 2005-2009

\begin{tabular}{|c|c|c|c|c|c|c|c|c|c|}
\hline \multirow[b]{2}{*}{ Indicadores } & \multicolumn{3}{|c|}{ Jovens de 18 a 35 anos } & \multicolumn{3}{|c|}{$\begin{array}{c}\text { Jovens de } 18 \text { a } 35 \text { anos com educação } \\
\text { média }\end{array}$} & \multicolumn{3}{|c|}{$\begin{array}{l}\text { Jovens de } 18 \text { a } 35 \text { anos beneficiários da } \\
\text { educaçâo técnica }\end{array}$} \\
\hline & $\begin{array}{l}\text { Situação } \\
\text { atual }\end{array}$ & $\begin{array}{l}\text { Alterando a taxa } \\
\text { de ocupaçẵo e a } \\
\text { remuneração }\end{array}$ & $\begin{array}{l}\text { Impacto } \\
\text { percentual }\end{array}$ & $\begin{array}{l}\text { Situação } \\
\text { atual }\end{array}$ & $\begin{array}{l}\text { Alterando a taxa } \\
\text { de ocupaçāa e a } \\
\text { remuneração }\end{array}$ & $\begin{array}{l}\text { Impacto } \\
\text { percentual }\end{array}$ & $\begin{array}{l}\text { Situação } \\
\text { atual }\end{array}$ & $\begin{array}{l}\text { Alterando a taxa } \\
\text { de ocupaçāo e a } \\
\text { remuneração }\end{array}$ & $\begin{array}{l}\text { Impacto } \\
\text { percentual }\end{array}$ \\
\hline Taxa de ocupação (PIA) & 73,2698 & 73,3064 & 0,05 & 76,5 & 76,6 & 0,10 & 78,2 & 82,2 & 5,09 \\
\hline Remuneração média & 862 & 863 & 0,12 & 1101 & 1103 & 0,16 & 946 & 1036 & 9.53 \\
\hline $\begin{array}{l}\text { Porcentagem em relação à } \\
\text { população total }\end{array}$ & & 31 & & & 14 & & & 0,3 & \\
\hline
\end{tabular}

veis, nesta avaliação do impacto agregado da expansão da educação técnica, optou-se por escolher aleatoriamente dentre os jovens com a mesma idade aqueles que se beneficiariam da educação técnica.

Nas tabelas 10 a 12 são apresentadas estimativas do impacto agregado da inserção no mercado de trabalho capixaba de uma coorte de 10 mil jovens com formação técnica. A tabela 10 apresenta o impacto sobre a taxa de ocupação e a remuneração média de três grupos de jovens entre $18 \mathrm{e}$ 35 anos: i) todos, ii) jovens com educação média completa e iii) 10 mil jovens beneficiados pela formação técnica. Os resultados ratificam o que já foi visto na seção 2: a formação técnica tem grande impacto sobre os diretamente beneficiados. De fato, esta tabela revela que a taxa de ocupação dos jovens beneficiados cresce 4 pontos percentuais, enquanto sua remuneração aumenta em R\$ 90,00 (10\%). Como uma coorte de beneficiários (10 mil jovens beneficiados) representa apenas $2 \%$ dos jovens no estado com educação média (cerca de 500 mil), o impacto sobre o conjunto dos jovens com educação média é, por conseguinte, apenas 1/50 do correspondente impacto sobre os diretamente beneficiados. De acordo, a taxa de ocupação deste grupo eleva-se em 0,08 pontos percentuais e a remuneração média em menos de R\$ 2,00 por mês. Por sua vez, como aproximadamente metade dos jovens (18 a 35 anos) no estado tem educação média completa, o impacto sobre o conjunto dos jovens é correspondente à metade do impacto sobre os jovens com educação média: 0,04 pontos percentuais adicionais na taxa de ocupação e R\$ 1,00 por mês adicional na remuneração.

Em resumo, a tabela 10 revela que, embora o impacto da formação técnica seja elevado entre os diretamente beneficiados, o impacto agregado, mesmo entre os jovens, é limitado, uma decorrência do limi- 
TABELA 11: IMPACTO IMEDIATO DE UMA COORTE DE EGRESSOS DA EDUCAÇÃO TÉCNICA SOBRE A DISTRIBUIIÇÃO DE REMUNERAÇÃO DE JOVENS ENTRE 18 E 35 ANOS: ESPÍRITO SANTO, 2005-2009

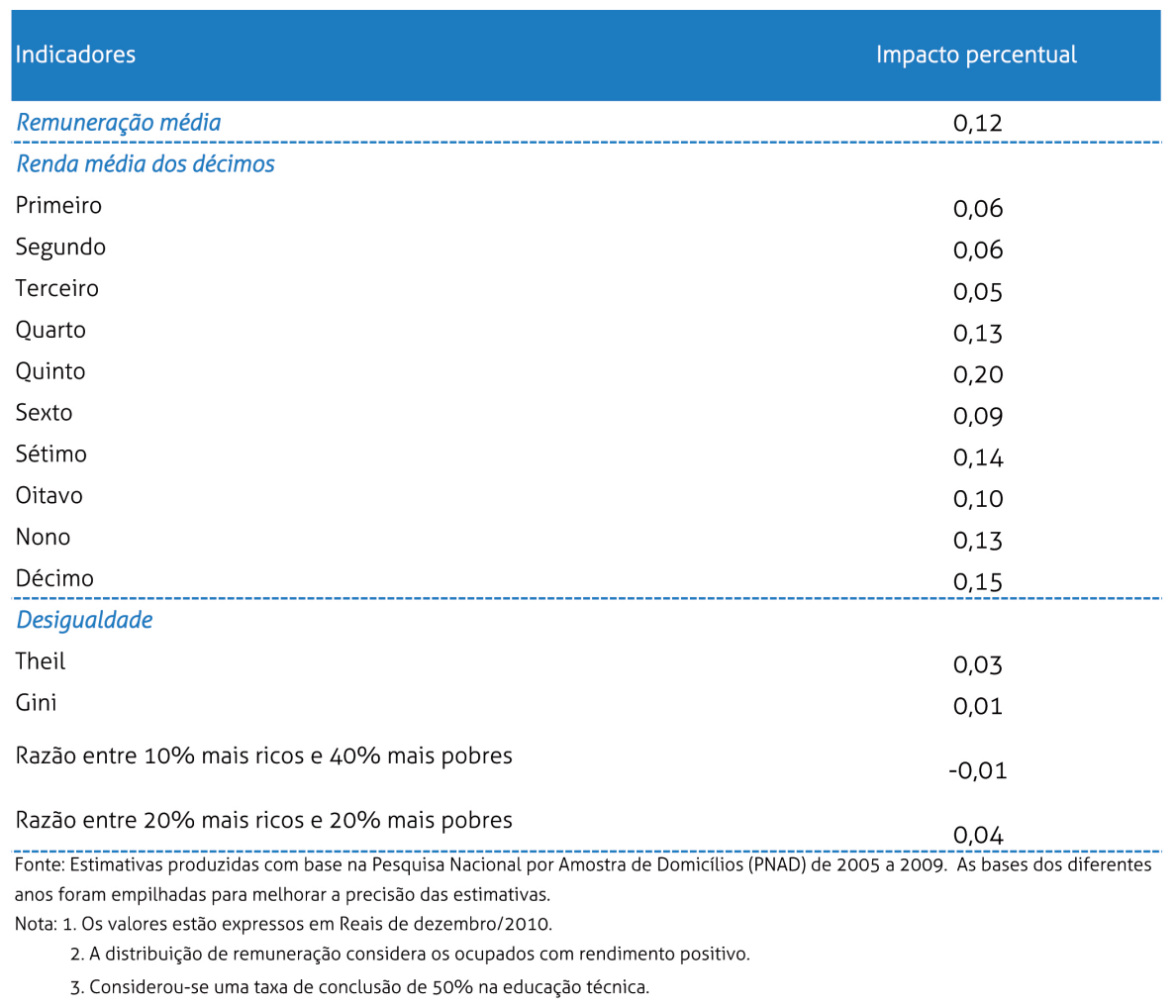

tado número de beneficiários em relação à população total de jovens. De fato, os 10 mil beneficiários representam apenas 1\% da população de jovens de 15 a 35 anos do estado. Por este motivo, o impacto da formação técnica de uma coorte sobre o conjunto da juventude acaba sendo apenas $1 \%$ do impacto sobre aqueles diretamente beneficiados.

Como foi visto na seção anterior, os jovens com educação média completa (potenciais beneficiários da formação técnica) não se encontram uniformemente espalhados ao longo da distribuição de renda, ao contrário, têm uma clara tendência a se concentrarem nas famílias com maio- res níveis de renda. Por conseguinte, o impacto de qualquer expansão na formação técnica não deverá ser distributivamente neutro. A tabela 11 confirma este resultado. Por um lado, esta tabela revela que a formação técnica eleva muito mais a remuneração dos trabalhadores jovens com alta remuneração que dos com baixa remuneração. De fato, conforme revela, o impacto da expansão da formação técnica sobre os décimos com maior remuneração é ao menos duas vezes maior que sobre os décimos com menor remuneração. Por este motivo, a expansão da educação técnica tende a aumentar o grau de desigualdade em remuneração entre os jovens. Em particular, leva a razão entre a renda dos 
TABELA 12: IMPACTO IMEDIATO DE UMA COORTE DE EGRESSOS DA EDUCAÇÃO TÉCNICA SOBRE A DISTRIBUIÇÃO DE RENDA E POBREZA DA POPULAÇÃO: ESPÍRITO SANTO, 2005-2009

\begin{tabular}{|c|c|c|c|}
\hline Indicadores & Situação atual & $\begin{array}{l}\text { Alterando a taxa de ocupação e a } \\
\text { remuneração }\end{array}$ & Impacto percentual \\
\hline Renda per capita & 626,69 & 627,00 & 0,05 \\
\hline \multicolumn{4}{|l|}{ Pobreza } \\
\hline Porcentagem de pobres & 17,4 & 17,4 & 0,00 \\
\hline Hiato de pobreza & 6,4 & 6,4 & $-0,02$ \\
\hline Severidade da pobreza & 3,7 & 3,7 & $-0,01$ \\
\hline \multicolumn{4}{|l|}{ Extrema pobreza } \\
\hline Porcentagem de extremamente pobres & 4,8 & 4,8 & 0,00 \\
\hline Hiato de extrema pobreza & 2,3 & 2,3 & 0,00 \\
\hline Severidade da extrema pobreza & 1,7 & 1,7 & 0,00 \\
\hline \multicolumn{4}{|l|}{ Desigualdade } \\
\hline Theil & 0,568 & 0,567 & $-0,02$ \\
\hline Gini & 0,531 & 0,531 & 0,00 \\
\hline $\begin{array}{l}\text { Razão entre } 10 \% \text { mais ricos e } 40 \% \text { mais } \\
\text { pobres }\end{array}$ & 15,3 & 15,3 & $-0,01$ \\
\hline $\begin{array}{l}\text { Razão entre } 20 \% \text { mais ricos e } 20 \% \text { mais } \\
\text { pobres }\end{array}$ & 16,5 & 16,5 & 0,04 \\
\hline \multicolumn{4}{|l|}{ Renda média dos décimos } \\
\hline Primeiro & 72 & 72 & 0,01 \\
\hline Segundo & 149 & 149 & 0,01 \\
\hline Terceiro & 207 & 207 & 0,03 \\
\hline Quarto & 263 & 263 & 0,07 \\
\hline Quinto & 333 & 333 & 0,08 \\
\hline Sexto & 416 & 416 & 0,05 \\
\hline Sétimo & 511 & 511 & 0,05 \\
\hline Oitavo & 672 & 672 & 0,05 \\
\hline Nono & 1006 & 1007 & 0,09 \\
\hline Décimo & 2640 & 2641 & 0,03 \\
\hline \multirow{2}{*}{\multicolumn{4}{|c|}{$\begin{array}{l}\text { Fonte: Estimativas produzidas com base na Pesquisa Nacional por } \\
\text { a precisão das estimativas. } \\
\text { Nota: } 1 \text {. Os valores estão expressos em Reais de dezembro/2010. }\end{array}$}} \\
\hline & & & \\
\hline 2. A distribuição de remuneração considera os oc & n rendimento posit & & \\
\hline
\end{tabular}

$20 \%$ mais ricos e a dos $20 \%$ mais pobres a crescer 0,04\% (ver tabela 12 ).

Por fim, investigou-se também o impacto sobre a renda familiar per capita e sua distribuição. Como a população do estado é cerca de três vezes a população jovem e, desta forma, por volta de 300 vezes maior que a população beneficiada, o impacto sobre a renda per capita é correspondentemente menor. Assim, enquanto o impac- to sobre a remuneração da população diretamente beneficiada é de $\mathrm{R} \$ 90,00$ por mês e sobre o conjunto dos jovens (18 a 35 anos) é de R\$ 1,00 por mês, o impacto sobre a renda per capita do estado é correspondentemente de RS 0,3 por mês. Como o impacto beneficia mais os trabalhadores jovens com alta remuneração que aqueles com baixa remuneração, expansões na formação técnica elevam a desigualdade de remuneração entre os trabalhadores jo- 
vens e, consequentemente, a desigualdade na distribuição da renda entre famílias. Como resultado deste impacto negativo sobre a igualdade, expansões na educação técnica têm impactos muito mais limitados sobre a renda dos mais pobres (e sobre a porcentagem de pobres) que sobre a renda per capita do conjunto da população.

\section{IMPACTOS DE LONGO PRAZO}

Na seção anterior, investigou-se o impacto sobre o mercado de trabalho e sobre a distribuição de renda da inserção no mercado de trabalho capixaba de uma única coorte de egressos da educação técnica. Nesta seção, investiga-se o impacto que uma política contínua de educação técnica poderia ter sobre os mesmos resultados. Contudo, antes de analisar a magnitude destes impactos, é fundamental descrever com algum detalhe o que se entende por uma política contínua de educação técnica.

Conforme já ressaltado, estima-se que, nos últimos anos, tem-se formado cerca de 10 mil técnicos a cada ano ${ }^{13}$. Por uma política contínua entende-se a situação em que a política atual viesse também a ser aplicada em todos os anos anteriores. O que se deseja investigar é como seria o desempenho do mercado de trabalho e a forma da distribuição de renda, caso o Espírito Santo sempre tivesse adotado uma política para educação técnica tão arrojada como a que adota atualmente. A operacionalização desta simulação requer ainda a definição de alguns conceitos. 0 mais importante é definir o que significa, em termos do número de egressos nos anos anteriores, ter adotado uma política tão arrojada como a atual. Três interpretações são possíveis.

Em primeiro lugar, poder-se-ia interpretar como um número absoluto de egressos igual ao atual para todos os anos anteriores. A dificuldade com esta abordagem é o fato de as coortes anteriores serem menores, o que resultaria no declínio da porcentagem de cada coorte com educação técnica de acordo com o ano de nascimento. Neste caso, o acesso à educação técnica estaria se tornado crescentemente mais difícil, na medida em que o número de vagas permanece fixo e o tamanho das coortes aumenta. Por este motivo esta interpretação não foi adotada.

Uma segunda abordagem seria congelar a proporção de cada coorte com educação técnica. Entretanto, como a taxa de conclusão na educação média tem-se expandido e só podem ter diploma de técnico aqueles com educação média completa, se a proporção da coorte com educação técnica for fixa, a porcentagem da coorte com educação média que tem formação técnica declinaria. Caso esta abordagem seja adotada, implicitamente se estaria por assumir que as vagas em educação técnica têm crescido mais lentamente do que o número de concluintes da educação média e, portanto, a chance de obter uma vaga na educação técnica para um aluno ou egresso da educação média estaria declinando. Por este motivo esta estratégia também não foi adotada.

Com objetivo de eliminar os inconvenientes destas duas abordagens anteriores, uma terceira foi adotada. O fator fixado 
neste caso foi a porcentagem de egressos da educação média que em cada coorte teve acesso à educação técnica. Nos últimos anos, a cada ano, em torno de $27 \mathrm{mil}$ jovens terminam o ensino médio e $10 \mathrm{mil}$ completam a formação técnica, o que leva $37 \%$ dos que completam o ensino médio a terem hoje formação técnica. Por conseguinte, nesta terceira abordagem, com vistas em avaliar o impacto agregado de uma política contínua de expansão da formação técnica, fixou-se a porcentagem de egressos da educação média que, em cada coorte, teve acesso à educação técnica em $37 \%$. Como cerca de $40 \%$ da população em idade ativa no estado tem educação média completa, o número de egressos utilizados na avaliação do impacto de uma política contínua foi de $15 \%$ da população em idade ativa, que em valores absolutos representam aproximadamente 350 mil egressos. Em outras palavras, estimou-se o impacto de uma política contínua de formação técnica comparando o desempenho do mercado de trabalho e a distribuição de renda atual do estado com a que teria, caso adicionalmente 350 mil pessoas em idade ativa do estado que têm educação média completa também tivessem formação técnica.

Os resultados obtidos são apresentados nas tabelas 13 a 15 . A tabela 13 apresenta o impacto que uma política contínua de formação técnica teria sobre os principais resultados do mercado de trabalho. Em termos de acesso ao trabalho, as estimativas apresentadas nesta tabela revelam que o impacto de longo prazo de uma política contínua seria de elevar a taxa de ocupação dos beneficiados em 3,8 pontos percentuais e da população em idade ativa (18 a 64 anos) em 0,5 ponto percentual. Em termos da remuneração dos trabalhadores, o impacto estimado é de um aumento de $\mathrm{R} \$ 151,00$ por mês (10\%) entre os beneficiários e R\$ 28,00 por mês em média para o conjunto da população em idade ativa. Note que, como uma expansão contínua da formação técnica deverá

- TABELA 13: IMPACTO DE LONGO PRAZO DE EGRESSOS DA EDUCAÇÃO TÉCNICA SOBRE A TAXA DE OCUPAÇÃO E A REMUNERAÇÃO DA POPULAÇÃO DE 18 A 64 ANOS: ESPÍRITO SANTO, 2005-2009

\begin{tabular}{|c|c|c|c|c|c|c|c|c|c|}
\hline \multirow[b]{2}{*}{ Indicadores } & \multicolumn{3}{|c|}{ População de 18 a 64 anos } & \multicolumn{3}{|c|}{$\begin{array}{l}\text { População de } 18 \text { a } 64 \text { anos com educação } \\
\text { média }\end{array}$} & \multicolumn{3}{|c|}{$\begin{array}{l}\text { População de } 18 \text { a } 64 \text { anos beneficiária da } \\
\text { educação técnica }\end{array}$} \\
\hline & $\begin{array}{l}\text { Situação } \\
\text { atual }\end{array}$ & $\begin{array}{l}\text { Alterando a taxa } \\
\text { de ocupação e a } \\
\text { remuneração }\end{array}$ & $\begin{array}{l}\text { Impacto } \\
\text { percentual }\end{array}$ & $\begin{array}{l}\text { Situação } \\
\text { atual }\end{array}$ & $\begin{array}{l}\text { Alterando a taxa } \\
\text { de ocupaçăo e a } \\
\text { remuneração }\end{array}$ & $\begin{array}{l}\text { Impacto } \\
\text { percentual }\end{array}$ & $\begin{array}{l}\text { Situaçāo } \\
\text { atual }\end{array}$ & $\begin{array}{l}\text { Alterando a taxa } \\
\text { de ocupaçẵo e a } \\
\text { remuneração }\end{array}$ & $\begin{array}{l}\text { Impacto } \\
\text { percentual }\end{array}$ \\
\hline Taxa de ocupaçāo (PIA) & 72,7 & 73,3 & 0,75 & 77,1 & 78,6 & 1,82 & 77,0 & 80,7 & 4,92 \\
\hline Remuneração média & 1092 & 1120 & 2,61 & 1590 & 1646 & 3,52 & 1520 & 1671 & 9,92 \\
\hline $\begin{array}{l}\text { Porcentagem em relaçāo à } \\
\text { populaçāo total do estado }\end{array}$ & \multicolumn{3}{|c|}{63} & \multicolumn{3}{|c|}{24} & \multicolumn{3}{|c|}{9} \\
\hline
\end{tabular}

Fonte: Estimativas produzidas com base na Pesquisa Nacional por Amostra de Domicilios (PNAD) de 2005 a 2009. As bases dos diferentes anos foram empilhadas para methorar a precisão das estimativas. Nota: 1. Os valores estāo expressos em Reais de dezembro/2010

2. Considerou-se uma taxa de conclusāo de $50 \%$ na educaçăo técnica.

13. Infelizmente não parecem existir informações precisas sobre o total de egressos da educação técnica no estado.

Revista Brasileira de Monitoramento e Avaliação | Número 1 | Janeiro-Junho de 2011 
atender em torno de $15 \%$ da população em idade ativa, o impacto médio sobre a população ativa corresponde a aproximadamente $15 \%$ (as simulações resultaram em $20 \%$ ) no caso do impacto direto sobre os beneficiários.

Como os beneficiários com educação média completa têm renda bem acima da média, o impacto da expansão contínua da educação técnica é elevar a desigualdade entre trabalhadores. Por exemplo, a razão entre a renda dos $20 \%$ mais bem remunerados e a dos $20 \%$ mais mal remunerados deve elevar-se em $2 \%$, uma vez que a educação técnica eleva a remuneração dos trabalhadores mais mal remunerados (20\% pior) em apenas $0,8 \%$ e em $3 \%$ a dos $20 \%$ mais bem remunerados (ver tabela 14).

Por fim, investigou-se o impacto de uma expansão contínua de educação técnica também sobre a renda per capita e sua distribuição (ver tabela 15). Conforme esta tabela revela, uma expansão contínua da educação técnica teria impactos visíveis sobre a distribuição de renda. $\mathrm{Na}$ presença desta política, a renda per capita do estado seria $2,5 \%$ mais elevada. O impacto seria particularmente mais

TABELA 14: IMPACTO DE LONGO PRAZO DE EGRESSOS DA EDUCAÇÃO TÉCNICA SOBRE A DISTRIBUIÇÃO DE REMUNERAÇÃO DA POPULAÇÃO DE 18 A 64 ANOS: ESPÍRITO SANTO, 2005-2009

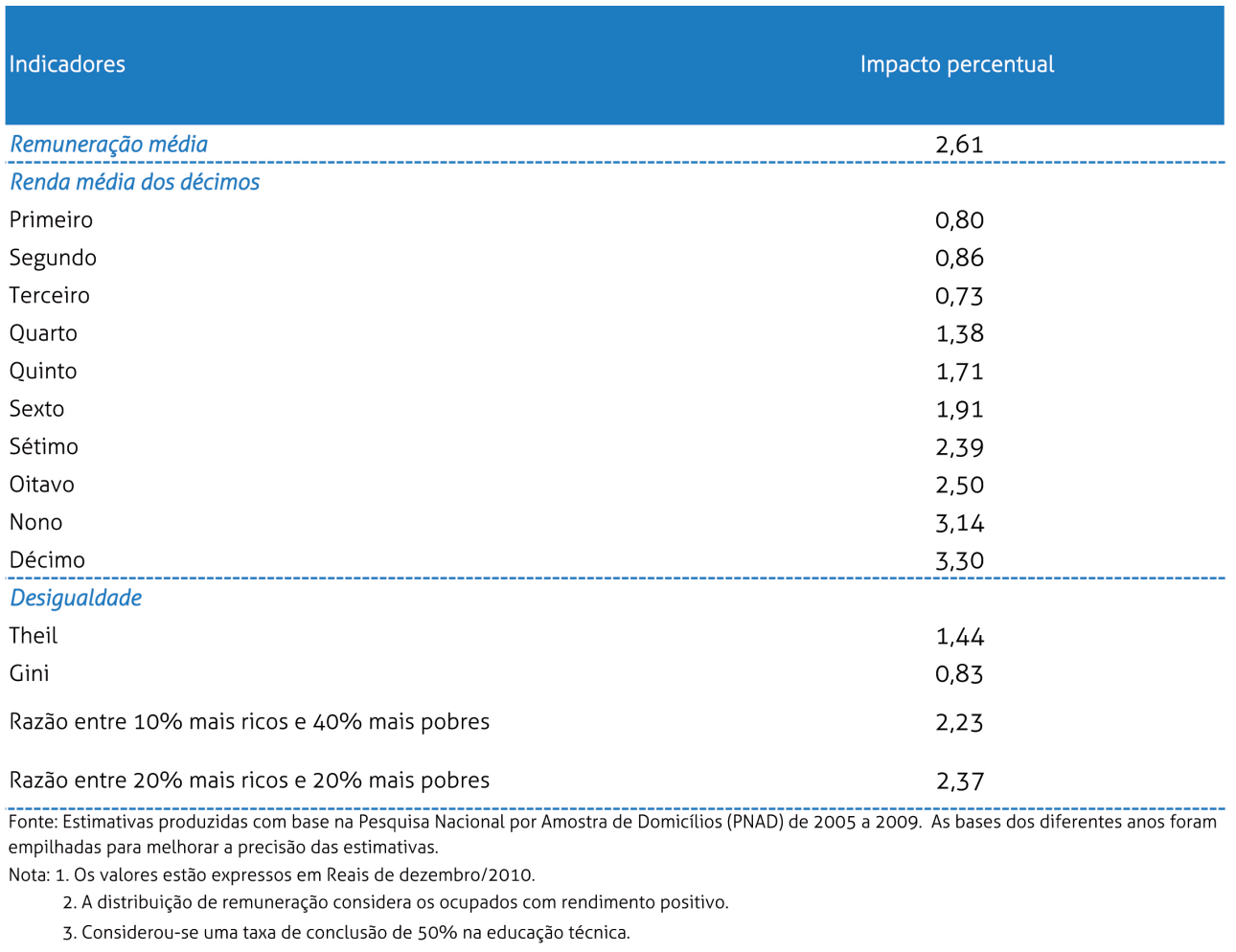


acentuado entre os grupos mais ricos. De fato, entre os $20 \%$ mais ricos, a renda per capita seria quase $3 \%$ mais elevada em virtude da educação técnica. Por sua vez, entre os $20 \%$ mais pobres, a elevação na renda média seria 0,6\%, o que leva o impacto desta política sobre a pobreza e a extrema pobreza a ser favorável, mas de magnitude extremamente limitada. Dado seu maior impacto sobre os grupos mais ricos, uma política contínua de educação técnica terá impactos negativos sobre a igualdade. Por exemplo, a razão entre a renda dos $20 \%$ mais ricos e $20 \%$ mais pobres deverá aumentar em $2 \%$ em virtude da expansão da educação técnica.

\section{TABELA 15: IMPACTO DE LONGO PRAZO DE EGRESSOS SOBRE A DISTRIBUIÇÃO DE RENDA E POBREZA DA POPULAÇÃO: ESPÍRITO SANTO, 2005-2009}

\begin{tabular}{|c|c|c|c|}
\hline Indicadores & Situação atual & $\begin{array}{l}\text { Alterando a taxa de ocupação e a } \\
\text { remuneração }\end{array}$ & Impacto percentual \\
\hline Renda per capita & 627 & 642 & 2,52 \\
\hline \multicolumn{4}{|l|}{ Pobreza } \\
\hline Porcentagem de pobres & 17,4 & 17,1 & $-1,62$ \\
\hline Hiato de pobreza & 6,4 & 6,4 & $-1,06$ \\
\hline Severidade da pobreza & 3,7 & 3,7 & $-0,81$ \\
\hline \multicolumn{4}{|l|}{ Extrema pobreza } \\
\hline Porcentagem de extremamente pobres & 4,8 & 4,8 & $-0,70$ \\
\hline Hiato de extrema pobreza & 2,3 & 2,3 & $-0,60$ \\
\hline Severidade da extrema pobreza & 1,7 & 1,6 & $-0,48$ \\
\hline \multicolumn{4}{|l|}{ Desigualdade } \\
\hline Theil & 0,568 & 0,574 & 1,08 \\
\hline Gini & 0,531 & 0,534 & 0,63 \\
\hline $\begin{array}{l}\text { Razão entre } 10 \% \text { mais ricos e } 40 \% \text { mais } \\
\text { pobres }\end{array}$ & 15,29 & 15,6 & 2,10 \\
\hline $\begin{array}{l}\text { Razão entre } 20 \% \text { mais ricos e } 20 \% \text { mais } \\
\text { pobres }\end{array}$ & 16,5 & 16,9 & 2,32 \\
\hline \multicolumn{4}{|l|}{ Renda média dos décimos } \\
\hline Primeiro & 72 & 73 & 0,46 \\
\hline Segundo & 149 & 150 & 0,80 \\
\hline Terceiro & 207 & 208 & 0,89 \\
\hline Quarto & 263 & 266 & 1,22 \\
\hline Quinto & 333 & 338 & 1,74 \\
\hline Sexto & 416 & 423 & 1,63 \\
\hline Sétimo & 511 & 522 & 2,15 \\
\hline Oitavo & 672 & 689 & 2,65 \\
\hline Nono & 1006 & 1035 & 2,88 \\
\hline Décimo & 2640 & 2721 & 3,08 \\
\hline \multicolumn{4}{|c|}{$\begin{array}{l}\text { Fonte: Estimativas produzidas com base na Pesquisa Nacional por Ar } \\
\text { das estimativas. }\end{array}$} \\
\hline Nota: 1 . Os valores estão expressos em Reais de dezem & & & \\
\hline $\begin{array}{l}\text { 2. A distribuição de remuneração considera os of } \\
\text { 3. Considerou-se uma taxa de conclusão de } 50 \%\end{array}$ & $\begin{array}{l}\text { om rendimento positi } \\
\text { ção técnica. }\end{array}$ & & \\
\hline
\end{tabular}

